\title{
Factors controlling the carbon isotope composition of dissolved inorganic carbon and methane in marine porewater: An evaluation by reaction- transport modelling
}

\author{
Patrick Meister ${ }^{\mathrm{a}, *}$, Bo Liu ${ }^{\mathrm{b}, 1}$, Arzhang Khalili ${ }^{\mathrm{c}, \mathrm{d}}$, Michael E. Böttcher ${ }^{\mathrm{b}, \mathrm{e}, \mathrm{f}}$, Bo Barker Jørgensen ${ }^{\mathrm{c}, \mathrm{g}}$ \\ ${ }^{a}$ Department for Geodynamics and Sedimentology, University of Vienna, Althanstrasse 14, 1090 Vienna, Austria \\ ${ }^{\mathrm{b}}$ Geochemistry \& Isotope Biogeochemistry Group, Department of Marine Geology, Leibniz Institute for Baltic Sea Research (IOW), Seestraße 15, 18119 Warnemünde, \\ Germany \\ ${ }^{\mathrm{c}}$ Max Planck Institute for Marine Microbiology, Celsiusstraße 1, 28359 Bremen, Germany \\ ${ }^{\mathrm{d}}$ Earth \& Space Sciences Program, School of Engineering and Science, Jacobs University, 28725 Bremen, Germany \\ ${ }^{\mathrm{e}}$ Marine Geochemistry, University of Greifswald, Friedrich-Ludwig-Jahn Str. 17a, 17489 Greifswald, Germany \\ ${ }^{\mathrm{f}}$ Department of Maritime Systems, Interdisciplinary Faculty, University of Rostock, Albert-Einstein-Straße 21, 18059 Rostock, Germany \\ ${ }^{g}$ Center for Geomicrobiology, Department of Bioscience, Aarhus University, Ny Munkegade 114, 8000 Aarhus, Denmark
}

\section{A R T I C L E I N F O}

\section{Keywords:}

Carbon isotopes

Methanogenesis

Anaerobic methane oxidation

Reaction-transport model

Methane

Marine porewater

\begin{abstract}
A B S T R A C T
Carbon isotope compositions of dissolved inorganic carbon (DIC) and methane $\left(\mathrm{CH}_{4}\right)$ in porewater of marine sediments at seafloor temperatures show very large variation covering a $\delta^{13} \mathrm{C}$ range from $-100 \%$ to $+35 \%$. These extreme values are the result of isotope fractionation during microbial carbon metabolism, but the combined effect of all factors controlling the isotope distributions is still not completely understood. We used a model approach to evaluate the effects of reaction and transport on carbon isotope distributions in modern sediment porewater under steady state. Simulated $\delta^{13} C_{\text {DIC }}$ profiles typically show negative values in the sulphate reduction zone and more positive values in the methanogenic zone. With increasing depth in the methanogenic zone, $\delta^{13} \mathrm{C}$ values approach a distribution where the offset of $\delta^{13} \mathrm{C}_{\mathrm{DIC}}$ from $\delta^{13} \mathrm{C}$ of total organic carbon (TOC) to more positive values is similar to the offset of $\delta^{13} \mathrm{C}_{\mathrm{CH} 4}$ to more negative values $\left(\delta^{13} \mathrm{C}_{\mathrm{DIC}}\right.$ and $\delta^{13} \mathrm{C}_{\mathrm{CH} 4}$ approach a symmetric distribution relative to $\delta^{13} \mathrm{C}_{\mathrm{TOC}}$ ). The model never exceeds this symmetry of the DIC-CH $\mathrm{CH}_{4}$ couple towards more positive values under steady-state conditions in a purely diffusive system.

Our model shows that to reach an offset in $\delta^{13} \mathrm{C}$ between DIC and $\mathrm{CH}_{4}$ in the order of 70\%, as frequently observed in methanogenic zones, a larger fractionation than reported from culture experiments with acetoclastic or autotrophic methanogens would be required. In fact, the observed isotope offset in natural systems would be consistent with the known inorganic equilibrium fractionation factor at in-situ temperature, which may suggest isotope exchange via a microbial pathway, during methanogenesis.

Furthermore, the model reproduces strongly negative $\delta^{13} \mathrm{C}_{\mathrm{CH} 4}$ values at the sulphate methane transition (SMT) as result of a reverse flux of carbon from DIC to $\mathrm{CH}_{4}$ during AOM. Such a reverse AOM has no influence on the $\delta^{13} \mathrm{C}_{\mathrm{DIC}}$ at the SMT as methane is almost completely consumed. Only at high sedimentation rate combined with low porosity, $\delta^{13} \mathrm{C}_{\mathrm{DIC}}$ values significantly more negative than $\delta^{13} \mathrm{C}_{\mathrm{TOC}}$ occur at the SMT.
\end{abstract}

\section{Introduction}

Some of the largest differences in stable carbon isotope composition in nature occur between dissolved inorganic carbon (DIC) and biogenic methane $\left(\mathrm{CH}_{4}\right)$ (Hoefs, 2018) as found in marine sediment porewater. Extremely ${ }^{13} \mathrm{C}$-depleted methane is observed with $\delta^{13} \mathrm{C}$ values more negative than $-100 \%$ (e.g., Claypool and Kaplan, 1974; Galimov,
2006; Heuer et al., 2009). In turn, extremely positive values of $+35 \%$ have been observed in DIC (e.g., Heuer et al., 2009). The variation of carbon fluxes into and out of the seafloor is thought to have contributed to some of the largest perturbations of the carbon cycle in Earth history. For example, the release of the greenhouse gas methane from the decomposition of gas hydrates has been suggested to have caused global warming events, such as the Palaeocene-Eocene thermal maximum,

\footnotetext{
* Corresponding author.

E-mail address: patrick.meister@alumni.ethz.ch (P. Meister).

${ }^{1}$ current address: Alfred-Wegener Institute - Helmholtz Centre for Polar and Marine Research, Am Handelshafen 12 , 27570 Bremerhaven, Germany.
} 
accompanied by major negative excursions in $\delta^{13} \mathrm{C}$ of atmospheric $\mathrm{CO}_{2}$ (Dickens, 1997, 1999). In contrast, positive excursions in $\delta^{13} \mathrm{C}$ in the Proterozoic carbonate record have been suggested to represent an increased burial rate of isotopically light organic carbon (e.g. Schidlowski et al., 1984; Knoll et al., 1986; cf. also Payne et al., 2004), although calculations by Hayes and Waldbauer Jr. (2006) suggest that burial rates would have to be unrealistically high to explain such large excursions. Instead, they suggested an early diagenetic origin of ${ }^{13} \mathrm{C}$-enriched carbonates related to methanogenesis (cf. Birgel et al., 2015).

Furthermore, a part of the buried organic carbon is remineralized and may be precipitated as carbonate in the deep subsurface, thereby becoming preserved in the geological record (Schrag et al., 2013). It remains unclear how both positive and negative carbon isotope compositions are incorporated into diagenetic carbonates, commonly showing a large range of values (Murata et al., 1967; Pisciotto and Mahoney, 1981; Kelts and McKenzie, 1984; Rodriguez et al., 2000; Moore et al., 2004). Temporal and spatial Variations in the C-isotope composition preserved in the diagenetic carbonate record were suggested to indicate changes in microbial activity in a dynamic sub-seafloor biosphere (Malone et al., 2002; Meister et al., 2007, 2008, 2019; Contreras et al., 2013; Meister, 2015; Wehrmann et al., 2016). However, further studies using reaction-transport models will be necessary to precisely interpret these carbon isotope signatures with respect to past dynamics of the deep biosphre.

While the global perturbations of carbon isotopes in ocean and atmosphere are a matter of ongoing debate, they are largely driven by the dynamics of carbon isotopes in the subsurface, but also these processes are incompletely understood. During the early phase of the Deep Sea Drilling Project (DSDP; e.g., Presley and Kaplan, 1971, 1972; Claypool et al., 1973; Goldhaber, 1974) C isotopes of $\mathrm{CH}_{4}$ and DIC were systematically measured in deep sub-seafloor porewater. While Bottinga (1969) suggested an equilibrium fractionation between the two species, it is generally assumed that the strong isotope fractionation is a result of enzymatic processes of microorganisms, as spontaneous reactions between DIC and $\mathrm{CH}_{4}$ would not occur at near-surface seabed temperatures. Fractionation occurs during fixation of $\mathrm{CO}_{2}$ by phytoplankton, resulting in the deposition of isotopically light organic carbon on the seafloor $\left(\delta^{13} \mathrm{C}\right.$ usually between -20 and $-30 \%$ ). This negative isotope signature is transferred into DIC produced by microbial organic carbon oxidation. Thus, $\delta^{13} \mathrm{C}_{\text {DIC }}$ values in marine porewater are typically negative in the zone of dissimilatory sulphate reduction (Claypool and Kaplan, 1974). In contrast, higher $\delta^{13} \mathrm{C}_{\text {DIC }}$ values result from methanogenesis due to strong kinetic fractionation, as $\mathrm{CH}_{4}$ is depleted in ${ }^{13} \mathrm{C}$ and the remaining DIC is enriched in ${ }^{13} \mathrm{C}$.

In several studies, fractionation factors during these processes have been calculated based on the isotopic composition of $\mathrm{C}$ species in marine porewater (e.g., Alperin et al., 1992; Whiticar, 1999) or in culture experiments (Krzycki et al., 1987; Londry et al., 2008). The experiments showed that fractionation also occurs during methanogenesis from disproportionating acetate into $\mathrm{CO}_{2}$ and $\mathrm{CH}_{4}$ (Londry et al., 2008). The isotopically lightest DIC is produced when $\mathrm{CH}_{4}$ is transported to the sulphate-methane transition zone (SMT) and is anaerobically oxidized to DIC (anaerobic oxidation of methane; AOM). This process is subject to smaller fractionation (Alperin et al., 1992). Holler et al. (2009) observed a reverse flux of ${ }^{14} \mathrm{C}$ label from DIC to methane during AOM, and this flux increases if the free energy difference of the forward reaction decreases at low sulphate concentration (Yoshinaga et al., 2014). This finding suggests a partial isotopic equilibration of methane and DIC through the enzymatic pathway. This raises the question whether (as suggested by Bottinga, 1969) also other pathways allow for equilibrium fractionation, including acetoclastic and autotrophic methanogenesis.

Besides the fractionation factor and mechanism, it also remains poorly understood how transport processes affect carbon isotope profiles of $\mathrm{CH}_{4}$ and DIC in a dynamic sedimentary porewater system. Nissenbaum and Presley (1972) suggested a closed-system Rayleigh fractionation model, which was further developed by Claypool and Kaplan (1974), Whiticar and Faber (1986), and Paull et al. (2000). Alperin et al. (1988) included the conversion of $\mathrm{CO}_{2}$ to $\mathrm{CH}_{4}$ during AOM in an open-system model, but they did not take into account the full stoichiometry of the overall processes of $\mathrm{CH}_{4}$ generation and consumption. Several open-system transient reaction-transport models have been developed since then, e.g. by Zeebe (2007), Chatterjee et al. (2011), Wu et al. (2018), and Chuang et al. (2019). While these studies addressed particular problems of diffusive transport, they only considered sub-sets of reactions affecting carbon isotope distribution in the sediment. Hence a better understanding of the carbon isotope distributions in sedimentary porewater awaits a more integrated model approach of the overall reactions and transport processes. An integrated reaction-transport model would also be fundamental to correctly interpret measurd carbon isotope profiles and ultimately to assess the global fluxes of carbon burial, rates of organic carbon remineralization and gas escape causing global perturbations in the carbon cycle.

In this study we developed a reaction-transport model to calculate $\delta^{13} \mathrm{C}$ values of $\mathrm{CH}_{4}$ and DIC in sulphate reduction and methanogenic zones of marine sediments. The model calculates the diffusive transport of sulphate, DIC, and $\mathrm{CH}_{4}$ and their carbon isotope compositions. Production and consumption of these solutes are linked via dissimilatory sulphate reduction and methanogenesis to the degradation rates of organic matter and via anaerobic methane oxidation to known kinetic rate laws. Carbon isotope fractionation is also linked to these reactions, using fractionation factors from the literature. Despite the great complexity of the carbon isotope system, this model setup provides a basic concept to calculate carbon isotope distributions in a diagenetic system. We demonstrate how a relatively small number of parameters, including the reactivity and the rate of deposition of organic matter on the seafloor, essentially control the patterns observed in measured profiles. The goal of the present study was to establish a general steadystate model for sediment carbon isotopes and test the sensitivity with respect to the magnitude of major controlling factors, in particular the isotope fractionation factors. This model allows us to understand cause and consequence relationships that are not intuitively understandable from sediment carbon isotope data. In comparison with measured isotope profiles, our model provides an instrument to understand how the distribution of stable carbon isotopes is controlled in natural environments.

\section{Modelling approach}

\subsection{Reaction-transport model}

Sulphate, methane, and DIC concentration profiles were computed as a function of sedimentation rate, diffusion rate, organic matter degradation rate, and anaerobic methane oxidation rate using the transient reaction transport model described in Meister et al. (2013). The following equations were used for sulphate (Eq. (1)), methane (Eq. (2)) and DIC (Eq. (3)):

$$
\begin{aligned}
\frac{\partial\left[\mathrm{SO}_{4}^{2-}\right]}{\partial \mathrm{t}}= & -\omega \frac{\partial\left[\mathrm{SO}_{4}^{2-}\right]}{\partial \mathrm{z}}+\frac{\mathrm{D}_{\mathrm{SO}_{4}^{2-}}}{\tau^{2}} \cdot \frac{\partial^{2}\left[\mathrm{SO}_{4}^{2-}\right]}{\partial \mathrm{z}^{2}}-\mathrm{m} \frac{1}{2} \mathrm{~s}_{\mathrm{TOC}}-\mathrm{s}_{\mathrm{AOM}} \\
\frac{\partial\left[\mathrm{CH}_{4}\right]}{\partial \mathrm{t}}= & -\omega \frac{\partial\left[\mathrm{CH}_{4}\right]}{\partial \mathrm{z}}+\frac{\mathrm{D}_{\mathrm{CH}_{4}}}{\tau^{2}} \cdot \frac{\partial^{2}\left[\mathrm{CH}_{4}\right]}{\partial \mathrm{z}^{2}}+(1-\mathrm{m}) \frac{1}{2} \\
& \mathrm{~S}_{\mathrm{TOC}}-\mathrm{S}_{\mathrm{AOM}}+\mathrm{v}_{\mathrm{CH}_{4}} \mathrm{~A} \frac{\partial\left(\left[\mathrm{CH}_{4}\right]-\left[\mathrm{CH}_{4}\right]_{\mathrm{sat}}\right)}{\partial \mathrm{z}}
\end{aligned}
$$

$$
\begin{aligned}
\frac{\partial[\mathrm{DIC}]}{\partial \mathrm{t}}= & -\omega \frac{\partial[\mathrm{DIC}]}{\partial \mathrm{z}}+\frac{\mathrm{D}_{\mathrm{HCO}_{3}^{-}}}{\tau^{2}} \cdot \frac{\partial^{2}[\mathrm{DIC}]}{\partial \mathrm{z}^{2}}+\mathrm{m} \mathrm{s}_{\mathrm{TOC}}+(1-\mathrm{m}) \frac{1}{2} \\
& \mathrm{~s}_{\mathrm{TOC}}+\mathrm{s}_{\mathrm{AOM}}
\end{aligned}
$$

where $\left[\mathrm{SO}_{4}{ }^{2-}\right],\left[\mathrm{CH}_{4}\right]$ and [DIC] are the concentrations of sulphate, methane, and DIC, respectively, $\mathrm{t}$ is time, $\omega$ is the sedimentation rate, $\mathrm{z}$ is the depth below seafloor, and $\mathrm{D}_{\mathrm{SO}_{4^{2-}}}, \mathrm{D}_{\mathrm{CH}_{4}}$, and $\mathrm{D}_{\mathrm{HCO}_{3}-}$ are the 
molecular diffusion constants for sulphate, methane and bicarbonate (which is the most abundant species of DIC under circum-neutral $\mathrm{pH}$ ). Diffusion constants for seawater at porewater temperature are from Schulz and Zabel (2006). A constant porosity $(\phi)$ of 0.7 was assumed and the tortuosity $(\tau)$ in Eqs. (1)-(3) was calculated according to Boudreau (1997) as $\tau^{2}=1-\ln \left(\phi^{2}\right)$. In addition, the effect of a changing porosity with depth was tested, using the decay function, $\phi=0.4+0.3$ $\cdot \mathrm{e}^{-\mathrm{z} / 150}$, in the general reaction-transport equations (Suppl. C) used previously (Arndt et al., 2009). Furthermore, $\mathrm{s}_{\mathrm{TOC}}$ and $\mathrm{s}_{\mathrm{AOM}}$ are source/ sink terms linked to metabolic turnover, whereby the Monod term m expresses the electron acceptor limitation during sulphate reduction (see below). The rise of supersaturated methane as gas phase was simulated by an upward advection term in Eq. (2), where $\mathrm{v}_{\mathrm{CH} 4}$ is the rise velocity of methane gas bubbles and the criterion $\mathrm{A}=1$ if $\left[\mathrm{CH}_{4}\right]>\left[\mathrm{CH}_{4}\right]_{\text {sat }}$ and $\mathrm{A}=0$ if $\left[\mathrm{CH}_{4}\right] \leq\left[\mathrm{CH}_{4}\right]_{\text {sat }}$ limits methane advection to the supersaturated depth interval (Meister et al., 2013). The saturation concentration of methane $\left[\mathrm{CH}_{4}\right]_{\text {sat }}$ was calculated from the polynomial equation (Dale et al., 2008a; Duan et al., 1992):

\subsection{Sources and sinks}

Sources and sinks of methane, sulphate, and DIC are stoichiometrically coupled to rates of organic carbon decay via the following simplified reactions for sulphate reduction (Eq. (5)) and methanogenesis (Eq. (6)):

$\mathrm{SO}_{4}^{2-}+2\left[\mathrm{CH}_{2} \mathrm{O}\right] \rightarrow \mathrm{HS}^{-}+2 \mathrm{HCO}_{3}^{-}+\mathrm{H}^{+}$

$2\left[\mathrm{CH}_{2} \mathrm{O}\right] \rightarrow \mathrm{CH}_{4}+\mathrm{CO}_{2}$

The sink of sulphate and source of methane, respectively, are calculated according to the stoichiometries in Eqs. (5) and (6) from the organic matter decay rate $s_{\text {TOC }}$ in Eqs. (1)-(3). Thereby $s_{\text {TOC }}$ is calculated from the derivative of organic matter decay with time (Eq. (7)):

$\mathrm{s}_{\mathrm{TOC}}=\partial\left(\frac{\mathrm{TOC} \rho_{\mathrm{S}}(1-\phi)}{100 \mathrm{M}_{\mathrm{C}} \phi}\right) / \partial \mathrm{t}$

where $\rho_{s}$ is the dry density of the sediment and $M_{C}$ is the molecular weight of carbon. $\partial \mathrm{t}$ is linked with $\partial \mathrm{z}$ through the sedimentation rate.

$\left[\mathrm{CH}_{4}\right]_{\text {sat }}=1.4388 \cdot 10^{-7} \mathrm{STP}-4.412 \cdot 10^{-5} \mathrm{TP}-406842 \cdot 10^{-5} \mathrm{SP}+4.129 \cdot 10^{-9} \mathrm{ST}+1.43465 \cdot 10^{-2} \mathrm{P}-1.6027 \cdot 10^{-6} \mathrm{~T}-1.2676 \cdot 10^{-6} \mathrm{~S}+4.9581 \cdot 10^{-4}$

where $\mathrm{T}$ is the temperature, $\mathrm{S}$ is the salinity, and $\mathrm{P}$ is the hydrostatic pressure. For the modelled cases a water depth of $200 \mathrm{~m}$ was assumed. Ocean water salinity was assumed for S. All parameters with values and units are listed in Table 1.
For organic matter decay, the reactive continuum (RC) model of Boudreau and Ruddick (1991) (Eq. (8)) was applied:

$\operatorname{TOC}(t)=\operatorname{TOC}_{0}\left[\frac{\mathrm{a}_{\mathrm{RC}}}{\left(\mathrm{a}_{\mathrm{RC}}+\mathrm{t}\right)}\right]^{\nu}$

where TOC(t) is the TOC remaining at sediment age $t, \mathrm{TOC}_{0}$ is the initial

Table 1

List of all parameters, their values and units.

\begin{tabular}{|c|c|c|c|c|}
\hline Parameter & Symbol & Value & Unit & Comments \\
\hline \multicolumn{5}{|l|}{ Domain and physical constraints: } \\
\hline Waterdepth & $\mathrm{z}_{\mathrm{W}}$ & 200 & $\mathrm{~m}$ & mbsl \\
\hline Domain size & $\mathrm{z}_{\mathrm{D}}$ & 200 & $\mathrm{~m}$ & mbsf \\
\hline Sedimentation rate & $\omega$ & $0.08\left(0.02-0.32^{\mathrm{a}}\right)$ & $\mathrm{m} / \mathrm{ka}$ & typical value for ocean margin sediments \\
\hline Temperature & $\mathrm{T}$ & 283 & $\mathrm{~K}$ & average temperature in marine sediment \\
\hline Pressure at the sediment/water interface & $\mathrm{P}$ & 20 & bar & based on water depth \\
\hline Salinity & $\mathrm{S}$ & 35 & & assumed normal seawater salinity \\
\hline \multicolumn{5}{|l|}{ Diffusion parameters: } \\
\hline Diffusion constant for sulphate & $\mathrm{D}_{\mathrm{SO} 42-}$ & 0.0214 & $\mathrm{~m}^{2} / \mathrm{a}$ & at $10^{\circ} \mathrm{C}$ (Schulz and Zabel (2006)) \\
\hline Diffusion constant for methane & $\mathrm{D}_{\mathrm{CH} 4}$ & 0.0334 & $\mathrm{~m}^{2} / \mathrm{a}$ & at $10^{\circ} \mathrm{C}$ (Schulz and Zabel (2006)) \\
\hline Diffusion constant for DIC & $\mathrm{D}_{\mathrm{HCO}-}$ & 0.0232 & $\mathrm{~m}^{2} / \mathrm{a}$ & at $10^{\circ} \mathrm{C}$ (Schulz and Zabel (2006)) \\
\hline Porosity & $\phi$ & $0.7\left(0.5-0.8^{\mathrm{a}}\right)$ & - & based on data in Einsele (2000) \\
\hline Concentration of $\mathrm{SO}_{4}{ }^{2-}$ in seawater & {$\left[\mathrm{SO}_{4}^{2-}\right]$} & 28 & $\mathrm{mM}$ & modern seawater \\
\hline Concentration of $\mathrm{CH}_{4}$ in seawater & {$\left[\mathrm{CH}_{4}\right]$} & 0 & $\mathrm{mM}$ & modern seawater \\
\hline \multicolumn{5}{|l|}{ TOC degradation: } \\
\hline Initial TOC (during sedimentation) & $\mathrm{TOC}_{0}$ & $1-8$ & wt $\%$ & variable \\
\hline Dry density of sediment & $\rho_{\mathrm{s}}$ & $2.6 * 10^{3}$ & $\mathrm{~kg} / \mathrm{l}$ & from measured data \\
\hline Initial age of organic matter & $a_{R C}$ & $4735-8,100,000$ & a & Boudreau and Ruddick (1991) \\
\hline RC-parameter & $v$ & $0.7\left(0.2-2^{\mathrm{a}}\right)$ & - & Boudreau and Ruddick (1991) \\
\hline \multicolumn{5}{|l|}{ Kinetics of metabolic reactions: } \\
\hline Monod constant of sulphate reduction & $\mathrm{K}_{\mathrm{S}}$ & 1 & $\mathrm{mM}$ & Arndt et al. (2006) \\
\hline Monod constant of AOM & $\mathrm{K}_{\mathrm{S}, \mathrm{AOM}}$ & 1 & $\mathrm{mM}$ & Nauhaus et al. (2002) \\
\hline First order rate constant for $\mathrm{CH}_{4}$ during $\mathrm{AOM}$ & $\mathrm{k}_{\mathrm{AOM}}$ & $4 * 10^{-2}$ & $\mathrm{a}^{-1}$ & based on thickness of AOM zone \\
\hline \multicolumn{5}{|l|}{ Isotope fractionation: } \\
\hline VPDB standard & $\mathrm{R}_{\mathrm{Std}}$ & 0.0111802 & $\%$ VPDB & Zhang et al. (1990) \\
\hline Isotopic composition of TOC & $\delta^{13} \mathrm{C}_{\mathrm{TOC}}$ & -25 & $\%$ VPDB & typical value for marine TOC \\
\hline Isotopic composition of DIC in seawater & $\delta^{13} \mathrm{C}_{\mathrm{DIC}, \mathrm{SW}}$ & 0 & $\%$ VPDB & modern seawater \\
\hline Fractionation factor acetoclastic methanogen. & $\alpha_{\mathrm{ac}}$ & $0.95-1$ & - & Whiticar et al. (1986); Londry et al. (2008) \\
\hline Fractionation factor autotrophic methanogen. & $\alpha_{\text {aut }}$ & $0.95-1$ & - & Whiticar et al. (1986); Londry et al. (2008) \\
\hline Kinetic fractionation factor for $\mathrm{AOM}$ & $\alpha_{\mathrm{AOM}}$ & $0.98-1$ & - & variable \\
\hline Equilibrium fr. factor $\mathrm{CH}_{4}-\mathrm{CO}_{2}$ & $\alpha_{\mathrm{eq}}$ & 0.93 & - & Richet et al. (1977), Horita (2001) at $10^{\circ} \mathrm{C}$ \\
\hline Rel. contribution of autotrophy & $\mathrm{r}$ & $0-1$ & - & variable \\
\hline Maximal AOM back flux rel. to net forw. flux & $\mathrm{s}_{\mathrm{AOMmax}}$ & $60,75,90$ & $\%$ & based on Yoshinaga et al. (2004) \\
\hline Fitting parameter for the back flux & b & 1 & $\mathrm{mM}$ & based on Yoshinaga et al. (2004) \\
\hline
\end{tabular}

${ }^{\mathrm{a}}$ in the suppl. material. 
TOC upon sedimentation, and $\mathrm{a}_{\mathrm{RC}}$ and $\nu$ are fitting parameters in the reactive continuum model. TOC at any depth $\mathrm{z}$ is estimated from TOC at time $t$ using the sedimentation rate, $\omega$. The parameter $a_{R C}$ describes the average lifetime of the more reactive compounds. The parameter $v$ is a "nondimensional parameter solely related to the shape of the distribution near $\mathrm{k}=0$ ", where $\mathrm{k}$ is the reactivity (Boudreau and Ruddick, 1991). As described in Arndt et al. (2006), electron acceptor limitation of organoclastic sulphate reduction was considered by a Monod-term $\mathrm{m}=\left[\mathrm{SO}_{4}{ }^{2-}\right] /\left(\left[\mathrm{SO}_{4}{ }^{2-}\right]+\mathrm{K}_{\mathrm{S}}\right)$ with a $\mathrm{K}_{\mathrm{S}}$ of $1 \mathrm{mM}(1.6 \mathrm{mM}$ was used by Boudreau and Westrich, 1984). As it has been recently found that a high-affinity sulphate-reduction may be induced at low sulphate concentrations $\left(\mathrm{K}_{\mathrm{S}}=2.6 \mu \mathrm{M}\right.$; Tarpgaard et al., 2011, 2017), the sensitivity of the model results for different half saturation constants was tested.

An additional sink of methane and sulphate and source of DIC in Eqs. (1), (2) and (3) is due to AOM:

$\mathrm{SO}_{4}^{2-}+\mathrm{CH}_{4} \rightarrow \mathrm{HS}^{-}+\mathrm{HCO}_{3}^{-}+\mathrm{H}_{2} \mathrm{O}$

During AOM, sulphate and methane are consumed (and DIC is produced) in a 1:1 ratio. As this reaction is catalysed by living microbial communities, we describe the rates of AOM by a Monod type kinetic function (Treude et al., 2003; Arndt et al., 2006).

$\mathrm{S}_{\mathrm{AOM}}=\mathrm{k}_{\mathrm{AOM}}\left[\mathrm{CH}_{4}\right] \frac{\left[\mathrm{SO}_{4}^{2-}\right]}{\mathrm{K}_{\mathrm{S}, \mathrm{AOM}}+\left[\mathrm{SO}_{4}^{2-}\right]}$

with a Monod constant $\mathrm{K}_{\mathrm{S}, \mathrm{AOM}}$ of $1 \mathrm{mM}$ (Arndt et al., 2006). The first order rate constant $\mathrm{k}_{\mathrm{AOM}}$ strongly affects the thickness of the overlap zone between methane and sulphate and we found a value of $4 * 10^{-2}$ $\mathrm{a}^{-1}$ to fit with the overlap zone commonly observed at SMTs. According to Knab et al. (2008), AOM is controlled by the kinetic drive while the thermodynamic drive only limits the feasibility of the AOMSRR process.

\subsection{Isotope fractionation}

Isotopic compositions were calculated from the modelled ratio $\mathrm{R}=\left[{ }^{13} \mathrm{C}\right] /\left[{ }^{12} \mathrm{C}\right]$ relative to the ratio $\mathrm{R}_{\mathrm{VPDB}}$ of the Vienna Peedee Belemnite standard (VPDB) according to:

$\delta^{13} \mathrm{C}=\frac{\mathrm{R}-\mathrm{R}_{\mathrm{VPDB}}}{\mathrm{R}_{\mathrm{VPDB}}} \cdot 1000$

The $\delta^{13} \mathrm{C}$ value is reported in permil VPDB, which is equivalent to milliUrey ('mU'; Brand and Coplen, 2012). Absolute concentrations of $\left[{ }^{13} \mathrm{CH}_{4}\right],\left[{ }^{12} \mathrm{CH}_{4}\right],\left[{ }^{13} \mathrm{DIC}\right]$, and $\left[{ }^{12} \mathrm{DIC}\right]$ were computed by separate reaction-transport equations (Eq. (2) for methane and Eq. (3) for DIC) for each isotope, and isotope fractionation was applied to the different source and sink terms, such that always:

$\mathrm{s}=\mathrm{s}_{13}+\mathrm{s}_{12}$

\subsubsection{Sulphate reduction}

Negligible carbon isotope fractionation was observed during organoclastic sulphate reduction (Claypool and Kaplan, 1974), and also fractionation factors determined in culture experiments (Londry and Des Marais, 2003) were near to one. Therefore, we assumed that this source of inorganic carbon has the same isotopic composition as the organic source pool.

\subsubsection{Methanogenesis}

Methanogenesis may occur via two major pathways: the autotrophic pathway using $\mathrm{CO}_{2}$ and $\mathrm{H}_{2}$ and the acetoclastic pathway using acetate. Although the overall stoichiometry from TOC to $\mathrm{CH}_{4}$ and DIC is the same for both pathways, they may show different isotope fractionation. Autotrophic methanogenesis yields a larger isotope fractionation than acetoclastic methanogenesis (with an apparent fractionation factor of 0.92-0.95; Whiticar et al., 1986). Whiticar et al. (1986) calculated a fractionation factor ${ }^{2}$ from measured porewater profiles, i.e. for the overall reaction. However, during autotrophic methanogenesis also a fermentation step has to be taken into account, which produces $\mathrm{H}_{2}$ as a driving force for autotrophic methanogenesis, but this fermentation also produces $\mathrm{CO}_{2}$. The overall reaction is thus:

$2\left[\mathrm{CH}_{2} \mathrm{O}\right] \stackrel{+2 \mathrm{H}_{2} \mathrm{O}}{\rightarrow} 2 \mathrm{CO}_{2}+4 \mathrm{H}_{2} \stackrel{-2 \mathrm{H}_{2} \mathrm{O}}{\rightarrow} \mathrm{CO}_{2}+\mathrm{CH}_{4}$

The source term for autotrophic methane production shows the isotopic ratio $\mathrm{R}_{\mathrm{CH}_{4}}$ (the isotopic ratio of the instantaneously produced $\left.\mathrm{CH}_{4}\right)$ :

$\mathrm{R}_{\mathrm{CH}_{4}}^{\prime}=\frac{\mathrm{s}_{13-\mathrm{CH}_{4} \text { aut }}}{\mathrm{s}_{12-\mathrm{CH}_{4} \text { aut }}}=\alpha_{\text {aut }} \cdot \mathrm{R}_{\mathrm{DIC}}$

$\mathrm{R}_{\mathrm{CH}_{4}}^{\prime}$ is equivalent to the ratio of the production rates of each isotopologue, if both the denominator and the numerator is divided by time. For DIC production the situation is more complex as two moles of $\mathrm{CO}_{2}$ are produced by fermentation with little or no fractionation, and one mole of $\mathrm{CO}_{2}$ is consumed by the autotrophic reaction with the fractionation factor $\alpha_{\text {aut }}$. Hence:

$\frac{\mathrm{s}_{13-\text { DICferm }}}{\mathrm{s}_{12-\text { DICferm }}}=\mathrm{R}_{\mathrm{TOC}}$

$\frac{\mathrm{s}_{13-\text { DICaut }}}{\mathrm{s}_{12-\text { DICaut }}}=\alpha_{\text {aut }} \cdot \mathrm{R}_{\text {DIC }}$

and

$\mathrm{S}_{\text {DIC (ferm+aut })}=\mathrm{s}_{\text {DICferm }}-\mathrm{S}_{\text {DICaut }}($ for each isotope $)$

However, the fractionation factors derived from the isotopic difference between $\delta^{13} \mathrm{C}_{\mathrm{CH}_{4}}$ and $\delta^{13} \mathrm{C}_{\mathrm{DIC}}$ also include the fermentation step according to Eq. (13), and hence the $\alpha$-values given in Whiticar et al. (1986) cannot be used for $\alpha_{\text {aut }}$. However, values for $\alpha_{\text {aut }}$ can be measured directly in culture experiments where the electron donor $\mathrm{H}_{2}$ was added (cf. references in Table 2). Most separation factors are in the order of $45 \%$ (isotope separation factor $\varepsilon=1000 \ln \alpha$ ) for autotrophic and $20 \%$ for acetoclastic methanogenesis.

During acetoclastic methanogenesis, one mole of each $\mathrm{CO}_{2}$ and $\mathrm{CH}_{4}$ is produced by the disproportionation of acetate:

$\mathrm{CH}_{3} \mathrm{COO}^{-}+\mathrm{H}^{+} \rightarrow \mathrm{CO}_{2}+\mathrm{CH}_{4}$

Thereby, the carboxyl carbon is turned into $\mathrm{CO}_{2}$ and the methyl carbon to $\mathrm{CH}_{4}$, and the isotopic composition of each would be pre-set by the ${ }^{13} \mathrm{C}$ distribution in the acetate molecule. This intramolecular isotope distribution would not produce large fractionation effects between $\mathrm{CO}_{2}$ and $\mathrm{CH}_{4}$ (Blair and Carter Jr., 1992; Sugimoto and Wada, 1993) but as the exact metabolic reaction pathway is unclear, exchange reactions between DIC and $\mathrm{CH}_{4}$ remain optional.

Independent of the pathway, the sources of methane and DIC are in isotopic proportion with the original organic matter multiplied by the fractionation factor $\alpha_{\mathrm{ac}}$ and 2- $\alpha_{\mathrm{ac}}$, respectively (Eqs. (19) and (20)).

$\frac{\mathrm{s}_{13-\mathrm{CH}_{4} \mathrm{ac}}}{\mathrm{s}_{12-\mathrm{CH}_{4} \mathrm{ac}}}=\alpha_{\mathrm{ac}} \cdot \mathrm{R}_{\mathrm{TOC}}$

$\frac{\mathrm{S}_{13-\mathrm{DICac}}}{\mathrm{S}_{12-\mathrm{DICac}}}=\left(2-\alpha_{\mathrm{ac}}\right) \cdot \mathrm{R}_{\mathrm{TOC}}$

The term $2-\alpha$ is due to mass balance. While the abundant isotope, ${ }^{12} \mathrm{C}$, can be assumed to be approximately invariant:

$\mathrm{s}_{12-\mathrm{CH} 4 \mathrm{ac}} \approx \mathrm{s}_{12-\mathrm{DICac}}$

the fractionation factors can be expressed as a ratio of the product over the reactant:

\footnotetext{
${ }^{2}$ The original values provided by Whiticar et al. (1986) $\left(\alpha^{\prime}=1.05-1.09\right)$ have been converted to $\alpha=1 / \alpha^{\prime}=R_{\text {product }} / R_{\text {Reactant }}$. Even though traditionally $\alpha^{\prime}$ is reported, this notation allows for simplification of the formulas provided below.
} 
Table 2

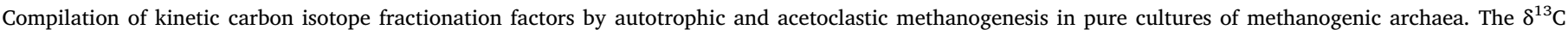

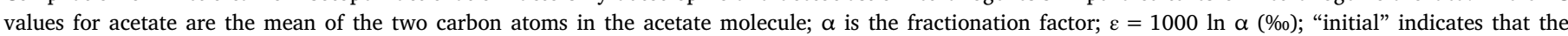
measurements were made at the beginning of the incubation time; "lim." indicates substrate limitation.

\begin{tabular}{|c|c|c|c|c|c|c|c|}
\hline$\delta^{13} \mathrm{C}$-Substrate & $\delta^{13} \mathrm{C}\left(\mathrm{CH}_{4}\right)$ & $\varepsilon$ & $\alpha$ & Conditions & Growth phase & Organism & Reference \\
\hline \% VPDB & $\%$ VPDB & $\%$ VPDB & & & & & \\
\hline \multicolumn{8}{|c|}{ Autotrophic methanogenesis } \\
\hline-10.2 & -56.2 & -46 & 0.955 & & & Methanosarcina barkeri & Krzycki et al. (1987) \\
\hline-19.9 & -64.5 & -44.6 & 0.956 & & & Methanosarcina barkeri & Krzycki et al. (1987) \\
\hline-31.2 & -71.5 & -40.3 & 0.961 & & & Methanosarcina barkeri & Londry et al. (2008) \\
\hline-31.2 & -76.6 & -45.4 & 0.956 & & initial & Methanosarcina barkeri & Londry et al. (2008) \\
\hline-28.5 & -79.6 & -51.1 & 0.950 & & $\mathrm{H}_{2}$-lim. & Methanosarcina barkeri & Londry et al. (2008) \\
\hline-28.5 & -108 & -79.5 & 0.924 & & $\mathrm{H}_{2}$-lim., initial & Methanosarcina barkeri & Londry et al. (2008) \\
\hline-46.7 & -50.6 & -3.9 & 0.996 & Glass fermentor, $35^{\circ} \mathrm{C}$ & Initial & Methanococcus vannielii & Botz et al. (1996) \\
\hline-42.8 & -99.3 & -56.5 & 0.945 & Glass fermentor, $35^{\circ} \mathrm{C}$ & End exp. phase & Methanococcus vannielii & Botz et al. (1996) \\
\hline-45.9 & -104.7 & -58.8 & 0.943 & Glass fermentor, $35^{\circ} \mathrm{C}$ & End stat. phase & Methanococcus vannielii & Botz et al. (1996) \\
\hline-45.7 & -92.3 & -46.6 & 0.954 & Ti fermentor, $35^{\circ} \mathrm{C}$ & Initial & Methanococcus vannielii & Botz et al. (1996) \\
\hline-45 & -111.7 & -66.7 & 0.935 & Ti fermentor, $35^{\circ} \mathrm{C}$ & End exp. phase & Methanococcus vannielii & Botz et al. (1996) \\
\hline-45.8 & -113.4 & -67.6 & 0.935 & Ti fermentor, $35^{\circ} \mathrm{C}$ & End stat. phase & Methanococcus vannielii & Botz et al. (1996) \\
\hline-23.6 & -39.7 & -16.1 & 0.984 & Glass fermentor, $45^{\circ} \mathrm{C}$ & Initial & Methanococcus thermolithotrophicus & Botz et al. (1996) \\
\hline-11.8 & -72 & -60.2 & 0.942 & Glass fermentor, $45^{\circ} \mathrm{C}$ & End exp. phase & Methanococcus thermolithotrophicus & Botz et al. (1996) \\
\hline-12.3 & -70.2 & -57.9 & 0.944 & Glass fermentor, $45^{\circ} \mathrm{C}$ & End stat. phase & Methanococcus thermolithotrophicus & Botz et al. (1996) \\
\hline-24.4 & -42.6 & -18.2 & 0.982 & Glass fermentor, $55^{\circ} \mathrm{C}$ & Initial & Methanococcus thermolithotrophicus & Botz et al. (1996) \\
\hline-15.4 & -71.6 & -56.2 & 0.945 & Glass fermentor, $55^{\circ} \mathrm{C}$ & End exp. phase & Methanococcus thermolithotrophicus & Botz et al. (1996) \\
\hline-19.9 & -80.5 & -60.6 & 0.941 & Glass fermentor, $55^{\circ} \mathrm{C}$ & End stat. phase & Methanococcus thermolithotrophicus & Botz et al. (1996) \\
\hline-47.7 & -106.2 & -58.5 & 0.943 & Ti fermentor, $55^{\circ} \mathrm{C}$ & Initial & Methanococcus thermolithotrophicus & Botz et al. (1996) \\
\hline-46.8 & -106.8 & -60 & 0.942 & Ti fermentor, $55^{\circ} \mathrm{C}$ & End exp. phase & Methanococcus thermolithotrophicus & Botz et al. (1996) \\
\hline-47.5 & -106 & -58.5 & 0.943 & Ti fermentor, $55^{\circ} \mathrm{C}$ & End stat. phase & Methanococcus thermolithotrophicus & Botz et al. (1996) \\
\hline-23.8 & -79.7 & -55.9 & 0.946 & Glass fermentor, $65^{\circ} \mathrm{C}$ & End exp. phase & Methanococcus thermolithotrophicus & Botz et al. (1996) \\
\hline-45.4 & -98.5 & -53.1 & 0.948 & Glass fermentor, $65^{\circ} \mathrm{C}$ & End stat. phase & Methanococcus thermolithotrophicus & Botz et al. (1996) \\
\hline-41.9 & -96.2 & -54.3 & 0.947 & Glass fermentor, $85^{\circ} \mathrm{C}$ & Initial & Methanococcus igneus & Botz et al. (1996) \\
\hline-38.1 & -89.2 & -51.1 & 0.950 & Glass fermentor, $85^{\circ} \mathrm{C}$ & End exp. phase & Methanococcus igneus & Botz et al. (1996) \\
\hline-39.2 & -83 & -43.8 & 0.957 & Glass fermentor, $85^{\circ} \mathrm{C}$ & End stat. phase & Methanococcus igneus & Botz et al. (1996) \\
\hline-43.1 & -101.7 & -58.6 & 0.943 & Ti fermentor, $85^{\circ} \mathrm{C}$ & Initial & Methanococcus igneus & Botz et al. (1996) \\
\hline-43.6 & -100.2 & -56.6 & 0.945 & Ti fermentor, $85^{\circ} \mathrm{C}$ & End exp. phase & Methanococcus igneus & Botz et al. (1996) \\
\hline-44.3 & -97.2 & -52.9 & 0.948 & Ti fermentor, $85^{\circ} \mathrm{C}$ & End stat. phase & Methanococcus igneus & Botz et al. (1996) \\
\hline \multicolumn{8}{|c|}{ Acetoclastic methanogenesis } \\
\hline-22.2 & -43.6 & -21.4 & 0.979 & & & Methanosarcina barkeri & Krzycki et al. (1987) \\
\hline-22.2 & -43.3 & -21.1 & 0.979 & & & Methanosarcina barkeri & Krzycki et al. (1987) \\
\hline-20.42 to -35.76 & -51.8 to -57.02 & -21.3 & 0.979 & & & Methanosarcina barkeri & Gelwicks et al. (1994) \\
\hline-20.2 to -21.4 & -40.2 to -40.8 & -19.2 & 0.981 & & & Lake water & Gelwicks et al. (1994) \\
\hline-30.9 & -53.8 & -22.9 & 0.977 & & & Methanosarcina barkeri & Londry et al. (2008) \\
\hline-30.9 & -65.7 & -34.8 & 0.966 & & initial & Methanosarcina barkeri & Londry et al. (2008) \\
\hline-30.9 & -25.7 & 5.2 & 1.005 & & substr.-lim. & Methanosarcina barkeri & Londry et al. (2008) \\
\hline \multicolumn{8}{|l|}{ AOM } \\
\hline & & & 0.988 to 0.961 & & 1) & & Holler et al. (2009) \\
\hline
\end{tabular}

1) The back fluxes reached between $5 \%$ and $13 \%$ of the net AOM rate (Holler et al., 2011).

For $\mathrm{CH}_{4}: \alpha_{\mathrm{ac}\left(\mathrm{CH}_{4}\right)}=\frac{\left({ }^{13} \mathrm{C}_{\mathrm{TOC}}-\mathrm{x}\right) /{ }^{12} \mathrm{C}_{\mathrm{TOC}}}{{ }^{13} \mathrm{C}_{\mathrm{TOC}} /{ }^{12} \mathrm{C}_{\mathrm{TOC}}}$

For DIC: $\alpha_{\mathrm{ac}(\mathrm{DIC})}=\frac{\left({ }^{13} \mathrm{C}_{\mathrm{TOC}}+\mathrm{x}\right) /{ }^{12} \mathrm{C}_{\mathrm{TOC}}}{{ }^{13} \mathrm{C}_{\mathrm{TOC}} /{ }^{12} \mathrm{C}_{\mathrm{TOC}}}$

where ${ }^{13} \mathrm{C}_{\mathrm{TOC}}$ and ${ }^{12} \mathrm{C}_{\mathrm{TOC}}$ stand for the concentrations of carbon isotopes in TOC, and $\mathrm{x}$ is the amount by which ${ }^{13} \mathrm{C}$ is increased or decreased in the product relative to ${ }^{13} \mathrm{C}_{\mathrm{TOC}}$. If Eq. 22 is solved for $\mathrm{x}$, and $\mathrm{x}$ is substituted in Eq. 23, it results that:

$\alpha_{\mathrm{ac}\left(\mathrm{CH}_{4}\right)}=2-\alpha_{\mathrm{ac}(\mathrm{DIC})}$

The value of $\alpha_{\mathrm{ac}}$ is generally smaller than $\alpha_{\text {aut }}$. A compilation of experimentally determined fractionation factors from pure cultures given in the literature is shown in Table 2.

The overall sources of methane and DIC from methanogenesis are then (for each isotope):

$\mathrm{s}_{\mathrm{CH}_{4} \text { meth }}=\mathrm{s}_{\mathrm{CH}_{4} \text { aut }}+\mathrm{s}_{\mathrm{CH}_{4} \text { ac }}$

$\mathrm{S}_{\text {DICmeth }}=\mathrm{S}_{\text {DIC }(\text { ferm }+ \text { aut })}+\mathrm{S}_{\text {DICac }}$

$s_{\text {DICmeth }}$ and $s_{\mathrm{CH} 4 m e t h}$ for the entire species are equivalent to $1 / 2 s_{\mathrm{TOC}}$ in Eqs. (2) and (3). The relative contribution of each pathway is determined by the degree of autotrophy, $r$ :

$\mathrm{r}=\frac{\mathrm{S}_{\mathrm{DIC}(\mathrm{ferm}+\mathrm{aut})}}{\mathrm{s}_{\mathrm{DIC}(\mathrm{ferm}+\mathrm{aut})}+\mathrm{S}_{\mathrm{DIC}-\mathrm{ac}}}$

\subsubsection{Anaerobic methane oxidation}

Kinetic fractionation during AOM is considered smaller than for methanogenesis (Alperin et al., 1988; Whiticar, 1999). Holler et al. (2009) found fractionation factors between 0.962 and 0.988 $\left(\alpha^{\prime}=1.012-1.039\right.$; which corresponds to an $\varepsilon$-value of $12-38 \%$ ) from enrichment culture experiments with consortia of anaerobic methaneoxidizing archaea and sulfate-reducing bacteria. The pure kinetic fractionation of the AOM reaction can be obtained from:

$\frac{\mathrm{s}_{13-\mathrm{AOM}}}{\mathrm{s}_{12-\mathrm{AOM}}}=\alpha_{\mathrm{AOM}} \cdot \mathrm{R}_{\mathrm{CH} 4}$

However, in experiments with radiolabelled DIC, Holler et al, (2011) demonstrated a reverse flux through the enzymatic pathway of AOM, i.e. some of the reaction product is channelled backwards to the substrate pool, which was interpreted to cause a partial isotopic equilibration between the coexisting $\mathrm{CH}_{4}$ and DIC pools. The true kinetic fractionation factor of the reverse reaction is not known, but it was 
suggested by Yoshinaga et al. (2014) that the difference in $\delta^{13} \mathrm{C}$ between $\mathrm{CH}_{4}$ and DIC approaches the isotope exchange equilibrium fractionation factor as the change in free energy by the reaction approaches chemical equilibrium. The theoretical equilibrium fractionation factor, $\alpha_{\mathrm{eq}}$, at reaction temperature was calculated by Richet et al. (1977) and Horita (2001).

To calculate the reverse flux we assume a forward reaction with rate $\mathrm{f}^{+}$and a backward reaction with rate $\mathrm{f}^{-}$, where $\mathrm{r}_{\mathrm{AOM}}=\mathrm{f}^{-} / \mathrm{f}^{+}$. In culture experiments, the back reaction reached $5 \%$ of the net AOM rate under fully marine sulphate concentration (Holler et al., 2011), but up to $78 \%$ under sulphate limitation in incubation experiments with sediment from Amon Mud Volcano (Nile Deep-Sea Fan; Yoshinaga et al., 2014). We used an empirical function fitted to the experimental data in those two studies to determine the dependence of $r_{\mathrm{AOM}}$ on the $\mathrm{SO}_{4}{ }^{2-}$ concentration:

$\mathrm{r}_{\mathrm{AOM}}=\mathrm{r}_{\mathrm{AOMmax}} \cdot \frac{\mathrm{b}}{\mathrm{b}+\left[\mathrm{SO}_{4}^{2-}\right]}$

where $r_{A O M m a x}(\%)$ is the maximal reverse flux and $b$ is a fitting parameter. If $s_{\mathrm{AOM}}$ is the net AOM rate $\left(\mathrm{s}_{\mathrm{AOM}}=\mathrm{f}^{+}-\mathrm{f}^{-}\right)$, we can find the rates of production of DIC and $\mathrm{CH}_{4}$ as follows:

$\mathrm{s}_{\mathrm{DIC}}=\mathrm{f}^{+}=1 /\left(1-\mathrm{r}_{\mathrm{AOM}}\right) \cdot \mathrm{s}_{\mathrm{AOM}}$

$\mathrm{s}_{\mathrm{CH} 4}=\mathrm{f}^{-}=\mathrm{r}_{\mathrm{AOM}} /\left(1-\mathrm{r}_{\mathrm{AOM}}\right) \cdot \mathrm{s}_{\mathrm{AOM}}$

To calculate the equilibrium isotope fractionation it is important to note that an isotopic equilibrium can only be reached if a chemical equilibrium of reactant and product is reached in the entire pool (Urey and Greiff, 1935), i.e. in the pool of $\mathrm{CH}_{4}$ and DIC in the porewater. However, isotopic equilibration may occur within the enzymatic pathway, which can be modelled by assuming a hypothetical compartment within the pathway (Fig. 1), in which equilibrium can be reached. Thereby, both the concentrations of species and overall concentrations of each isotope are conserved:

${ }^{13} \mathrm{CH}_{4}+{ }^{12} \mathrm{DIC} \leftrightarrow{ }^{12} \mathrm{CH}_{4}+{ }^{13} \mathrm{DIC}$

Although the forward and backward reaction rates $\mathrm{s}_{\mathrm{DIC}}$ and $\mathrm{s}_{\mathrm{CH} 4}$ are different, two assumptions can be made based on the equilibrium reaction (Eq. 32): (1) The total rate of DIC production before equilibration, $s_{\text {DIC }}$, and after equilibration, $s_{\text {DIC }}^{\prime}$, remains the same (this is also true for $\mathrm{CH}_{4}$ ):

${ }^{13} \mathrm{~s}_{\text {DIC }}^{\prime}+{ }^{12} \mathrm{~s}_{\text {DIC }}^{\prime}={ }^{13} \mathrm{~s}_{\text {DIC }}+{ }^{12} \mathrm{~s}_{\text {DIC }}$

(2) The turnover rate of the sum of each isotope is not changed by the equilibration (here shown for ${ }^{13} \mathrm{C}$ ):
${ }^{13} \mathrm{~S}_{\text {DIC }}^{\prime}+{ }^{13} \mathrm{~s}_{\mathrm{CH} 4}^{\prime}={ }^{13} \mathrm{~S}_{\mathrm{DIC}}+{ }^{13} \mathrm{~s}_{\mathrm{CH} 4}$

If we define $\eta$ as the rate of transfer of each isotope from one isotopologue to another during equilibration it follows, from the conservation of the molecules, $\mathrm{CH}_{4}$ and DIC (Eq. (33)), and the conservation of isotopes, ${ }^{13} \mathrm{C}$ and ${ }^{12} \mathrm{C}$ (Eq. (34)), that the change in concentration per time is the same value, $\eta$, for all four isotopologues:

${ }^{13} \mathrm{~s}_{\text {DIC }}^{\prime}={ }^{13} \mathrm{~s}_{\mathrm{DIC}}+\eta$

${ }^{12} \mathrm{~s}_{\text {DIC }}^{\prime}={ }^{12} \mathrm{~S}_{\mathrm{DIC}}-\eta$

${ }^{13} \mathrm{~s}_{\mathrm{CH} 4}^{\prime}={ }^{13} \mathrm{~s}_{\mathrm{CH} 4}-\eta$

${ }^{12} \mathrm{~s}_{\mathrm{CH} 4}^{\prime}={ }^{12} \mathrm{~s}_{\mathrm{CH} 4}+\eta$

The value of $\eta$ is determined by the thermodynamic equilibrium fractionation factor $\alpha_{\mathrm{eq}}$, which can be expressed as the ratio of production rates of each isotopologue after equilibration:

$\alpha_{\text {eq }}=\frac{{ }^{13} \mathrm{~s}_{\mathrm{CH} 4}^{\prime} /{ }^{12} \mathrm{~s}_{\mathrm{CH} 4}}{{ }^{13} \mathrm{~s}_{\mathrm{DIC}}^{\prime} /{ }^{12} \mathrm{~s}_{\mathrm{DIC}}^{\prime}}=\frac{\left({ }^{13} \mathrm{~s}_{\mathrm{CH} 4}-\eta\right)\left({ }^{12} \mathrm{~s}_{\mathrm{DIC}}-\eta\right)}{\left({ }^{12} \mathrm{~s}_{\mathrm{CH} 4}+\eta\right)\left({ }^{13} \mathrm{~s}_{\mathrm{DIC}}+\eta\right)}$

The value of $\eta$, thus, depends on $\alpha_{\text {eq }}$ as well as on the initial isotopic compositions of the $\mathrm{CH}_{4}$ and DIC fluxes into the pathway. Eq. (39) is a quadratic equation that can be solved for $\eta$ (Suppl. A). The new production and consumption rates of each isotopologue are found by substituting $\eta$ in Eqs. 35-38.

\subsection{Initial conditions and boundary conditions}

The input parameters $\mathrm{TOC}_{0}, \mathrm{a}_{\mathrm{RC}}, \nu$, and $\omega$ were systematically varied within a range representative for marine sediments. For each set of parameters the model was run until a steady state was reached. Initial conditions were $0 \mathrm{mM}$ sulphate, methane and DIC at all depths. The boundary conditions were set to $28 \mathrm{mM}$ sulphate and $2 \mathrm{mM}$ DIC at the sediment/water interface. Both ${ }^{12} \mathrm{CH}_{4}$ and ${ }^{13} \mathrm{CH}_{4}$ were set to a zero gradient at the upper boundary to prevent large artefacts at low $\mathrm{CH}_{4}$ concentration. The $\delta^{13} \mathrm{C}$ of DIC in seawater was fixed at $0 \%$. The lower boundary conditions were defined as zero gradient for sulphate, methane, and DIC. It is important to notice that the domain size has a significant influence on the redox zones since more methane is produced in a thicker sequence of sediment. In nature, the domain size is given by the thickness of the sedimentary sequence. In the model, only the organic matter decaying within the domain contributes to metabolism, whereas the organic matter buried below the lower domain boundary is excluded from the model reactions. Because the rate of organic matter decay decreases with time and depth according to the

\section{Isotope equilibration}

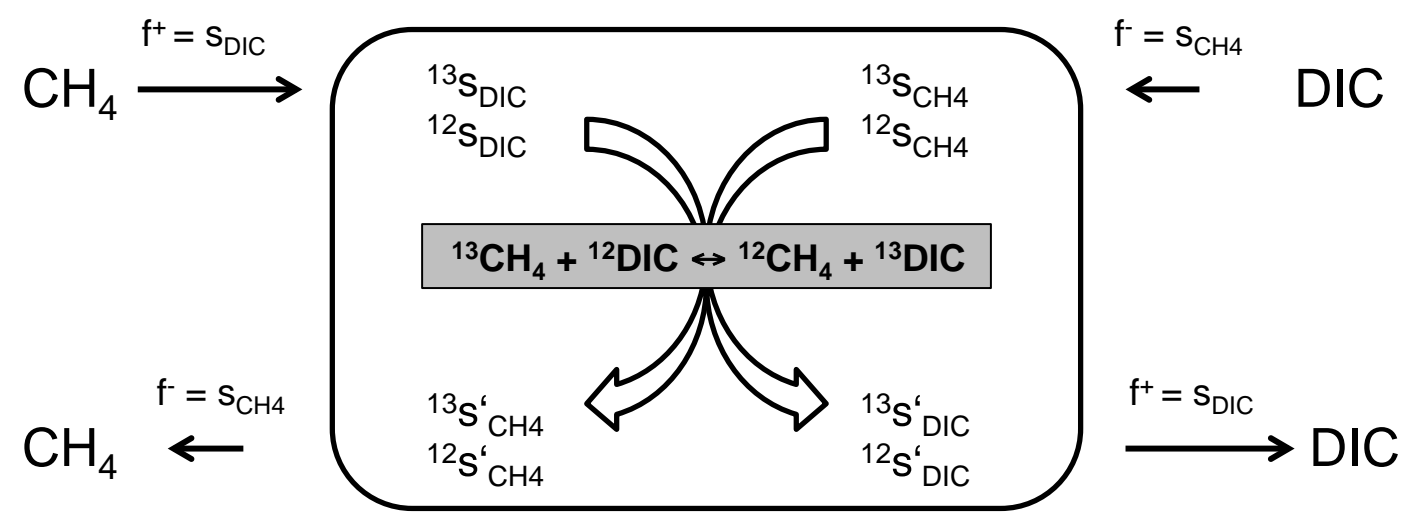

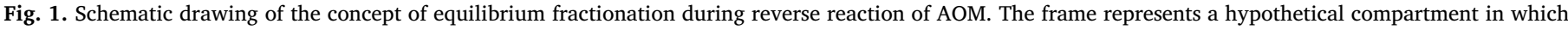
isotope exchange takes place. Please note that despite different forward and reverse fluxes, mass balance is maintained through Eqs. (33) and (34). 
reactive continuum model, which is similar to a power law function, the decay below the lower domain boundary is negligible if a sufficiently large domain is considered (cf. Meister et al., 2013). To make sure this holds true for the modelled carbon isotope profiles we also tested the sensitivity of sulphate and methane profiles to changes in the domain size.

\subsection{Numerical solution}

The sulphate, methane and DIC profiles determined by Eqs. 1-3 were simulated using the Lattice-Boltzmann method (LBM; WolfGladrow, 2000; Sukop and Thorne Jr., 2007). In the LBM, the evolution of concentration $\mathrm{C}$ is modelled by a single relaxation time scheme (Bhatnagar-Gross-Krook scheme; BGK; Bhatnagar et al., 1954):

$\mathrm{f}_{\mathrm{i}}\left(\mathrm{z}+\mathrm{e}_{\mathrm{i}} \Delta \mathrm{t}, \mathrm{t}+\Delta \mathrm{t}\right)-\mathrm{f}_{\mathrm{i}}(\mathrm{z}, \mathrm{t})=-\frac{1}{\mathrm{t}_{\mathrm{R}}}\left(\mathrm{f}_{\mathrm{i}}(\mathrm{z}, \mathrm{t})-\mathrm{f}_{\mathrm{i}}^{\mathrm{eq}}(\mathrm{z}, \mathrm{t})\right)+\mathrm{s}_{\mathrm{i}}$

where $f_{i}(z, t)$ is the single-particle distribution function with velocity $e_{i}$ at position $\mathrm{z}$ and time $\mathrm{t}$, and $\Delta \mathrm{t}$ is the time increment. In the 1-dimensional lattice with 3 velocities (D1Q3), the velocities are given by the three non-dimensional vectors: $\mathrm{e}_{0}=0, \mathrm{e}_{1}=1$, and $\mathrm{e}_{2}=-1$. The function $\mathrm{f}_{\mathrm{i}}^{\mathrm{eq}}(\mathrm{z}, \mathrm{t})$ is the equilibrium distribution function:

$\mathrm{f}_{\mathrm{i}}^{\mathrm{eq}}(\mathrm{z}, \mathrm{t})=\mathrm{w}_{\mathrm{i}} \mathrm{C}\left(1-3 \mathrm{e}_{\mathrm{i}} \omega\right)$

The weight parameter $\mathrm{w}_{\mathrm{i}}$ (i.e. the proportion in which the concentration $C$ is transported along the vectors $e_{0}, e_{1}$, and $e_{2}$ ) is given by $\mathrm{w}_{0}=2 / 3, \mathrm{w}_{1}=\mathrm{w}_{2}=1 / 6$. A source or sink is expressed as $\mathrm{s}_{\mathrm{i}}=\mathrm{w}_{\mathrm{i}} \mathrm{s}$, where $s$ is the source/sink term defined in Eqs. (1)-(3). Furthermore, $t_{R}$ is the non-dimensional relaxation time. It can be shown that the advection/diffusion reaction equation can be derived from the LatticeBoltzmann equation (Eq. (40)) through a Chapman-Enskog expansion procedure (Wolf-Gladrow, 2000). The quantity $t_{R}$ can then be adjusted to tune the transport coefficients through relation $t_{R}=3 D+1 / 2$ with the diffusion coefficient $\mathrm{D}$. The macroscopic concentration (i.e. the concentration measureable in a volume of porewater) is obtained by $\mathrm{C}=\mathrm{f}_{0}+\mathrm{f}_{1}+\mathrm{f}_{2}$.

\subsection{Model parameterization}

Parameter values or ranges of values used in our model are listed in Table 1. Concentration profiles of sulphate and methane computed over a large range of different organic carbon input, organic carbon degradation rates, and sedimentation rates are described and discussed in Meister et al. (2013). For a better overview, we list all variables used to calculate the $\delta^{13} \mathrm{C}$ profiles of DIC and $\mathrm{CH}_{4}$ shown in the figures in Table 3 . These cases are representative for a large range of marine sedimentary porewater profiles, i.e. differently condensed or expanded redox zonations and different reactivities of organic matter as discussed in detail in Meister et al. (2013). We discuss general features in comparison with a few selected measured profiles.

For comparison with the model results, we compiled datasets of $\delta^{13} \mathrm{C}_{\mathrm{CH}_{4}}$ and $\delta^{13} \mathrm{C}_{\text {DIC }}$ of several sites from the literature: Blake Ridge (DSDP Site 533; $3191 \mathrm{~m}$ water depth; Galimov and Kvenvolden, 1982; and ODP Sites 994, 995, and 997; 2798, 2779, and 2770 m water depth; Paull et al., 2000), Cascadia Margin (IODP Site U1329; $946 \mathrm{~m}$ water depth; Heuer et al., 2009), Bullseye vent (Cascadia Margin, Site C-2; $1311 \mathrm{~m}$ water depth; Pohlman et al., 2008), and the Peru Trench (ODP Site 1230; $5086 \mathrm{~m}$ water depth; Meister et al., 2011).

\section{Model results}

Typical sulphate, methane, and DIC concentration profiles are displayed for case $B_{2}$ (Table 3 ) in Fig. 2, showing a decreasing sulphate concentration and increase of methane below the SMT at $10 \mathrm{mbsf}$. DIC concentration increases with depth with a kink at the SMT. The same case was used to test the sensitivity of the $\delta^{13} \mathrm{C}$-profiles towards different fractionation factors (Fig. 3). The simulated $\delta^{13} \mathrm{C}_{\mathrm{CH} 4}$ profiles show values more negative than $-70 \%$ at a fractionation factor $\alpha_{\mathrm{ac}}=0.95$ for acetoclastic methanogenesis (Fig. 3a). The values are constant with depth, and the profiles show a regular spacing with incremental changes of $\alpha_{\mathrm{ac}}$. Values are less negative for autotrophic methanogenesis if the same values are used for the fractionation factor (ca. $-60 \%$ for $\alpha_{\text {aut }}=0.95$; Fig. $3 \mathrm{~b}$ ), and the profiles show a curvature towards more negative values at the SMT. Isotope values in DIC decrease with depth in the sulphate zone and show invariably the value of bulk TOC at the SMT. Below the SMT, $\delta^{13} \mathrm{C}_{\text {DIC }}$ increases asymptotically to a more positive value in the methanogenic zone. The values are more positive for acetoclastic methanogenesis than for autotrophic methanogenesis. The effect of the degree of autotrophy is also shown in Fig. 3c, whereby Fig. 3d demonstrates that at $r=0.5$ the fractionation factors of the two pathways are exchangeable.

At constant fractionation factors the effect of the amount and reactivity of organic matter in the sediment is tested, using $\alpha_{\mathrm{ac}}=\alpha_{\mathrm{aut}}=0.95$ and $\mathrm{r}=0.5$ for case $\mathrm{B}_{3}$ (Table 3). Fig. 4 shows how $\delta^{13} \mathrm{C}_{\text {DIC }}$ values increase with increasing TOC $_{0}$, while the SMT is shallowing. Also $\delta^{13} \mathrm{C}_{\mathrm{CH} 4}$ values slightly increase with increasing $\mathrm{TOC}_{0}$. However, the $\delta^{13} \mathrm{C}_{\mathrm{DIC}}$ remains near $\delta^{13} \mathrm{C}_{\mathrm{TOC}}$ at the SMT under all conditions.

A significant change in both $\delta^{13} \mathrm{C}_{\mathrm{CH}_{4}}$ and $\delta^{13} \mathrm{C}_{\mathrm{DIC}}$ is observed with changing $\mathrm{a}_{\mathrm{RC}}$, the initial age of organic matter in the reactive continuum model. Fig. 5 displays the effect of changing $\mathrm{a}_{\mathrm{RC}}$ at constant SMT depth. As shown in Meister et al. (2013), two values for $\mathrm{a}_{\mathrm{RC}}$ can be found, for which the SMT is at the same depth. Fig. 5a and b show their effect for a SMT at $10 \mathrm{mbsf}$ and $20 \mathrm{mbsf}$, respectively. As the two different $a_{R C}$ values differ more in the latter case (Fig. 5b), also the difference in the isotopic compositions are larger for different $\mathrm{a}_{\mathrm{RC}}$. Generally, the more refractory organic matter (larger $\mathrm{a}_{\mathrm{RC}}$ ) results in a more symmetrical distribution of $\delta^{13} \mathrm{C}_{\mathrm{CH}_{4}}$ and $\delta^{13} \mathrm{C}_{\text {DIC }}$ with respect to $\delta^{13} \mathrm{C}_{\mathrm{TOC}}$. A similar effect occurs if the parameter $\nu$ in the reactive continuum model is varied (Fig. S1, Suppl. B). This value describes the distribution of reactivity in the reactive continuum. The isotope profiles are most sensitive to this parameter if $\mathrm{a}_{\mathrm{RC}}$ is small, resulting in much more negative $\delta^{13} \mathrm{C}_{\mathrm{CH}_{4}}$ and $\delta^{13} \mathrm{C}_{\mathrm{DIC}}$ values at small $\nu$. Also in this case, the $\delta^{13} \mathrm{C}_{\text {DIC }}$ remains near to $\delta^{13} \mathrm{C}_{\mathrm{TOC}}$ at the SMT.

Sedimentation rate and porosity have a different effect on the isotope profiles than the initial TOC content (Fig. S2; Suppl. C). At high sedimentation rate and low porosity, respectively, the $\delta^{13} \mathrm{C}_{\text {DIC }}$ values are more positive in the methanogenic zone, but distinctly more negative than $\delta^{13} \mathrm{C}_{\mathrm{TOC}}$ at the SMT. These negative values are reached without the effect of fractionation due to AOM or reverse AOM flux (see below). $\delta^{13} \mathrm{C}_{\mathrm{CH}_{4}}$ values are less negative at higher sedimentation rate and lower porosity. Isotope profiles at decreasing porosity with depth are not fundamentally different from profiles at a constant porosity. A rapid decrease of porosity also leads to a very shallow SMT.

So far, no fractionation during AOM is taken into account. Fig. 6 shows the results of different AOM kinetic fractionation factors of the net forward reaction in combination with equilibrium fractionation as a result of the reverse flux. In order to determine the dependence of the reverse flux on the $\mathrm{SO}_{4}{ }^{2-}$ concentration, an empirical function (Eq. (29)) is fitted to the $\mathrm{SO}_{4}{ }^{2-}$-dependent rate function (Fig. 6a). Three different values for $\mathrm{r}_{\mathrm{AOMmax}}(60 \%, 75 \%$, and $90 \%)$ are used for the isotope model as shown in Fig. $6 \mathrm{~b}$. The $\delta^{13} \mathrm{C}_{\mathrm{CH}_{4}}$ profiles show a pronounced minimum at the SMT and an upward increase in the sulphatereduction zone. The minimum is not present if zero reverse flux is considered. Varying the fractionation factor $\alpha_{\mathrm{AOM}}$ has a strong effect on the $\delta^{13} \mathrm{C}_{\mathrm{CH}_{4}}$ profile in the sulphate reduction zone, with a steep increase at $\alpha_{\mathrm{AOM}}=0.98$ and a strong decrease if no kinetic fractionation is taken into account $\left(\alpha_{\mathrm{AOM}}=1\right.$; Fig. $\left.6 \mathrm{c}\right)$. Increasing the rate of AOM $\left(\mathrm{k}_{\mathrm{AOM}}\right)$ results in both more negative $\delta^{13} \mathrm{C}_{\mathrm{CH}_{4}}$ values at the SMT and more positive values in the sulphate reduction zone (Fig. 6d). None of the 
Table 3

List of all variables tested in the modelled cases. The cases are shown in Figs. 1 through 6 and Figs. S1 and S2.

\begin{tabular}{|c|c|c|c|c|c|c|c|c|c|c|c|c|}
\hline Figure & Case & $\mathrm{z}_{\mathrm{SMT}}$ & $\mathrm{TOC}_{0}$ & $a_{\mathrm{RC}}$ & $v$ & $\omega$ & $\mathrm{k}_{\mathrm{AOM}}$ & $\alpha_{\text {aut }}$ & $\alpha_{\mathrm{ac}}$ & $\mathrm{r}$ & $\alpha_{\mathrm{AOM}}$ & $\mathrm{r}_{\mathrm{AOMmax}}$ \\
\hline & & $(\mathrm{m})$ & $(w t \%)$ & (a) & & $(\mathrm{m} / \mathrm{ka})$ & & & & & & $(\%)$ \\
\hline & B1 & 10 & 4 & 7850 & 0.7 & 0.08 & & & & & & \\
\hline & B2 & 10 & 2 & 47,500 & 0.7 & 0.08 & & & & & & \\
\hline & B3 & 10 & 2 & 872,000 & 0.7 & 0.08 & & & & & & \\
\hline & B4 & 10 & 4 & $3,860,000$ & 0.7 & 0.08 & & & & & & \\
\hline & $\mathrm{C} 1$ & 20 & 4 & 4735 & 0.7 & 0.08 & & & & & & \\
\hline & $\mathrm{C} 2$ & 20 & 2 & 17,800 & 0.7 & 0.08 & & & & & & \\
\hline & $\mathrm{C} 3$ & 20 & 2 & $2,600,000$ & 0.7 & 0.08 & & & & & & \\
\hline & C4 & 20 & 4 & $8,100,000$ & 0.7 & 0.08 & & & & & & \\
\hline 1 & B2 & 10 & 2 & 47,500 & 0.7 & 0.08 & 0.04 & & & & & \\
\hline $2 a$ & B2 & 10 & 2 & 47,500 & 0.7 & 0.08 & 0.04 & & 0.95 & 0 & & \\
\hline $2 b$ & B2 & 10 & 2 & 47,500 & 0.7 & 0.08 & 0.04 & 0.95 & & 1 & & \\
\hline $2 c$ & B2 & 10 & 2 & 47,500 & 0.7 & 0.08 & 0.04 & 0.95 & 0.95 & & & \\
\hline $2 d$ & $\mathrm{~B} 2$ & 10 & 2 & 47,500 & 0.7 & 0.08 & 0.04 & & & 0.5 & & \\
\hline 3 & (B3) & & $1,2,4,8$ & 872,000 & 0.7 & 0.08 & 0.04 & 0.95 & 0.95 & 0.5 & & \\
\hline $4 a$ & B2, B3 & 10 & 2 & & 0.7 & 0.08 & 0.04 & 0.95 & 0.95 & 01 & & \\
\hline $4 \mathrm{~b}$ & $\mathrm{C} 2, \mathrm{C} 3$ & 20 & 2 & & 0.7 & 0.08 & 0.04 & 0.95 & 0.95 & 01 & & \\
\hline $5 b$ & B3 & 10 & 2 & 872,000 & 0.7 & 0.08 & 0.04 & 0.95 & 0.95 & 0.5 & 0.99 & \\
\hline $5 c$ & B3 & 10 & 2 & 872,000 & 0.7 & 0.08 & 0.04 & 0.95 & 0.95 & 0.5 & & 75 \\
\hline $5 \mathrm{~d}$ & B3 & 10 & 2 & 872,000 & 0.7 & 0.08 & 0.04 & 0.95 & 0.95 & 0.5 & 0.99 & 75 \\
\hline 6 & B3 & 10 & 2 & 872,000 & 0.7 & 0.08 & $0.00004-0.4$ & 0.95 & 0.95 & 0.5 & & \\
\hline S2a & & 10 & 4 & 1850 & 0.2 & 0.08 & 0.04 & 0.95 & 0.95 & 0.5 & & \\
\hline S2a & B1 & 10 & 4 & 7850 & 0.7 & 0.08 & 0.04 & 0.95 & 0.95 & 0.5 & & \\
\hline S2a & & 10 & 4 & 15,000 & 1 & 0.08 & 0.04 & 0.95 & 0.95 & 0.5 & & \\
\hline S2a & & 10 & 4 & 42,500 & 2 & 0.08 & 0.04 & 0.95 & 0.95 & 0.5 & & \\
\hline S2b & & 10 & 4 & 480,000 & 0.2 & 0.08 & 0.04 & 0.95 & 0.95 & 0.5 & & \\
\hline S2b & B4 & 10 & 4 & $3,860,000$ & 0.7 & 0.08 & 0.04 & 0.95 & 0.95 & 0.5 & & \\
\hline S2b & & 10 & 4 & $6,000,000$ & 1 & 0.08 & 0.04 & 0.95 & 0.95 & 0.5 & & \\
\hline S2b & & 10 & 4 & $13,200,000$ & 2 & 0.08 & 0.04 & 0.95 & 0.95 & 0.5 & & \\
\hline S3a & & & 2 & 872,000 & 0.7 & $0.02-0.32$ & 0.04 & 0.95 & 0.95 & 0.5 & & \\
\hline S3b & & & 2 & 872,000 & 0.7 & 0.08 & 0.04 & 0.95 & 0.95 & 0.5 & & \\
\hline S3c & & & 2 & 872,000 & 0.7 & 0.08 & 0.04 & 0.95 & 0.95 & 0.5 & & \\
\hline
\end{tabular}

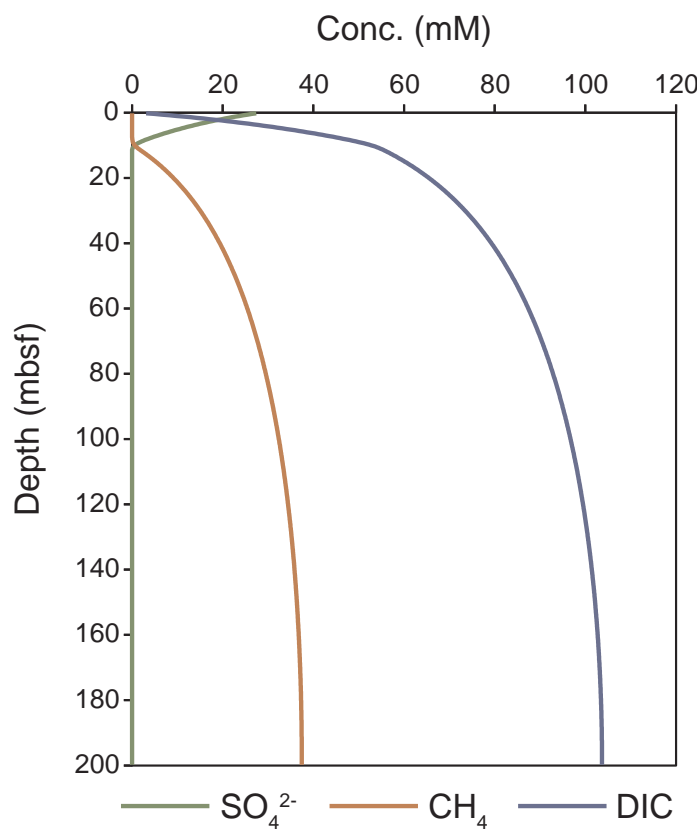

Fig. 2. Modelled sulphate, methane, and DIC concentration profiles using the parameters for the exemplary case $\mathrm{B}_{2}$ listed in Table 3 . Sulphate is depleted at 10 mbsf. An abrupt change in the slope of the DIC profile at the SMT at $10 \mathrm{mbsf}$ is due to production of DIC by AOM. Below the SMT, $\mathrm{CH}_{4}$ and DIC increase almost in parallel.

fractionation effects of AOM affect the $\delta^{13} \mathrm{C}_{\mathrm{CH}_{4}}$ profiles below the SMT, and no changes occur throughout the entire $\delta^{13} \mathrm{C}_{\mathrm{DIC}}$ profiles.

A further effect tested is the diffusive escape of $\mathrm{CH}_{4}$ at the sedimentwater interface. This was achieved assuming case $\mathrm{B}_{3}$ but with a $\mathrm{TOC}_{0}$ of
$8 \mathrm{wt} \%$, such that the SMT is at a very shallow depth (Fig. 7). Changing $\mathrm{k}_{\mathrm{AOM}}$ from $4 \cdot 10^{-1}$ to $4 \cdot 10^{-5} \mathrm{a}^{-1}$ results in a lower AOM rate, such that $\mathrm{AOM}$ is no more capable of retaining all $\mathrm{CH}_{4}$ within the sediment. The resulting profiles show an increase in $\delta^{13} \mathrm{C}_{\text {DIC }}$ in the sulphate reduction zone, while no significant effect occurs in the $\delta^{13} \mathrm{C}_{\mathrm{CH} 4}$ profile. No effect is noticed in the isotope profiles at greater depth in the methanogenic zone.

\section{Discussion}

\subsection{Carbon isotope profiles and their sensitivity to fractionation factors}

Each fractionation factor, $\alpha_{\mathrm{aut}}$ and $\alpha_{\mathrm{ac}}$ was systematically varied between 0.95 and 1 , which comprises the span of fractionation factors provided for pure cultures of methanogenic archaea in the literature (Table 2). The relative contribution of each pathway is expressed by the degree of autotrophy, $\mathrm{r}=$ autotrophic/total methanogenesis, which was varied between 0 and 1 . According to several studies, autotrophic methanogenesis is the dominant pathway in marine sediments (e.g. Beulig et al., 2018). Heuer et al. (2009) found that $r$ may vary with depth, but results must in all cases lie between the end-members modelled here.

In the case of pure acetoclastic methanogenesis (Fig. $3 \mathrm{a}$ ), $\mathrm{CH}_{4}$ shows a constant $\delta^{13} \mathrm{C}$ with depth, whereby the offset from $\delta^{13} \mathrm{C}_{\mathrm{TOC}}$ (set to $-25 \%$ ) depends linearly on $\alpha_{\mathrm{ac}}$. Normalized production rates for each isotope relative to TOC degradation rates are also constant with depth and depend linearly on the fractionation factor (not shown). Thus, also the $\delta^{13} \mathrm{C}$ of the entire $\mathrm{CH}_{4}$ or DIC pool at steady state depend linearly on $\alpha_{\mathrm{ac}}$. In the case of $\alpha_{\mathrm{ac}}=1$, no fractionation occurs and $\delta^{13} \mathrm{C}$ of both DIC and $\mathrm{CH}_{4}$ are identical to $\delta^{13} \mathrm{C}_{\mathrm{TOC}}$, except near the sediment/water interface where $\delta^{13} \mathrm{C}_{\text {DIC }}$ shows a mixing gradient with DIC from seawater (with $\delta^{13} \mathrm{C}_{\text {DIC }}=0 \%$ ). In cases of $\alpha_{\mathrm{ac}}<1, \delta^{13} \mathrm{C}_{\text {DIC }}$ remains unchanged (i.e. near to $\delta^{13} \mathrm{C}_{\mathrm{TOC}}$ ) in the sulphate reduction zone (due to production 
A

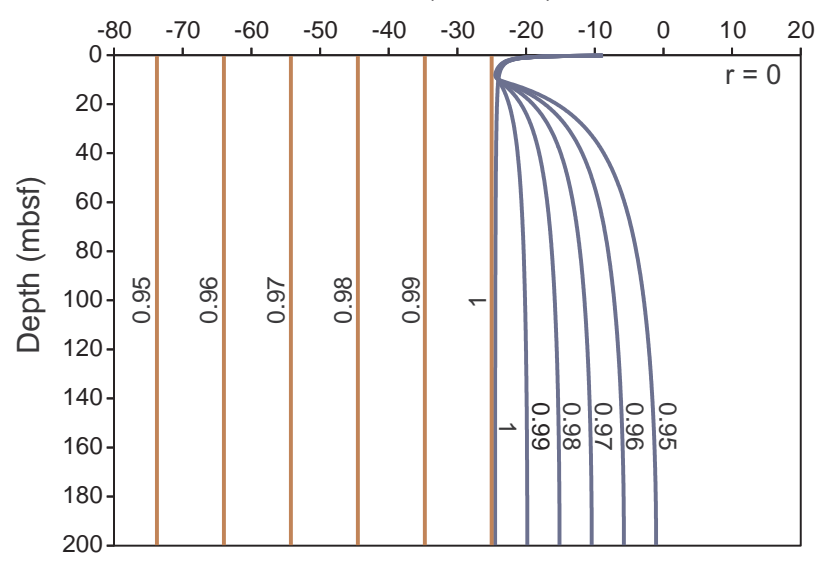

C

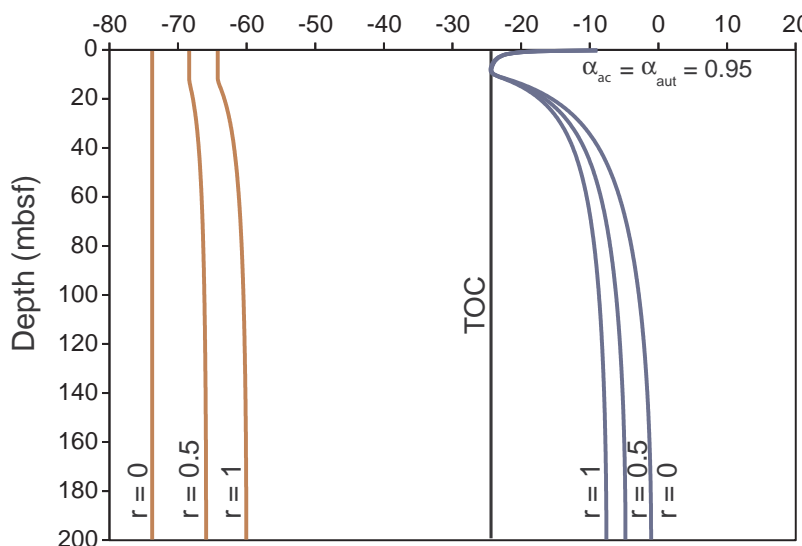

B

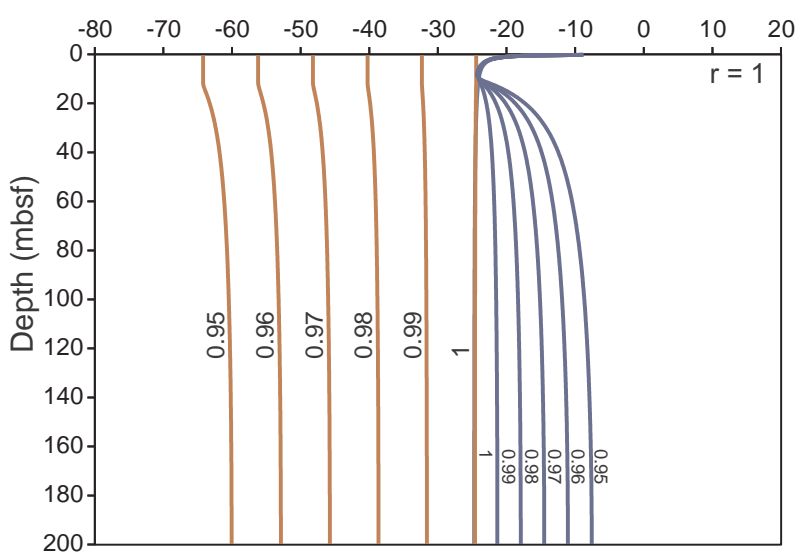

D

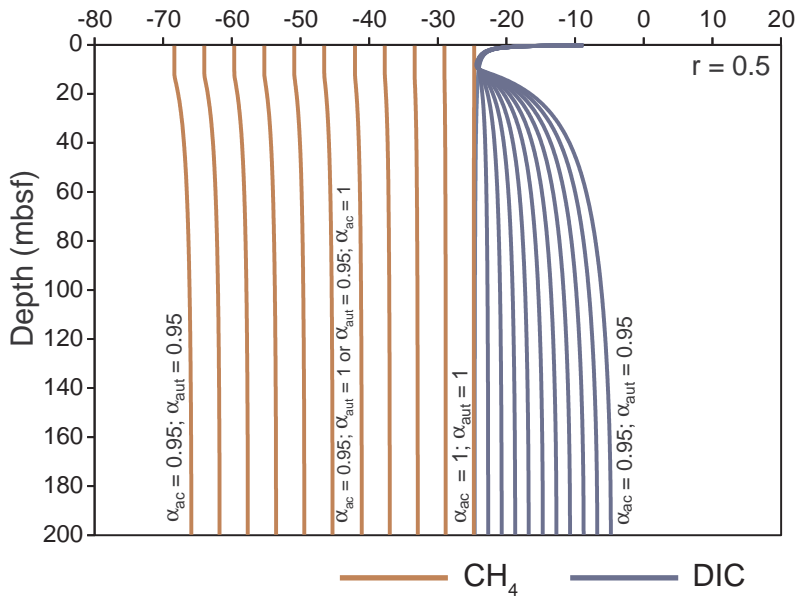

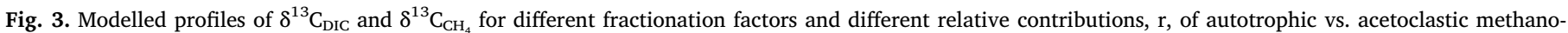

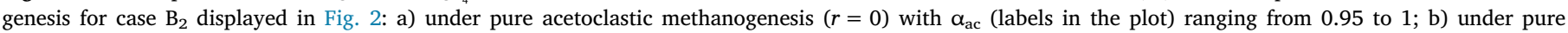

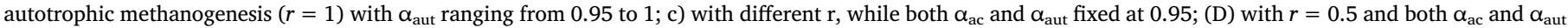
ranging from 0.95 to 1 . At $r=0.5, \alpha_{a c}$ and $\alpha_{\text {aut }}$ are exchangeable.

of DIC from TOC with no assumed fractionation) and increases in the methanogenic zone to reach a plateau with linear dependence on $\alpha_{\mathrm{ac}}$. In general, the offset of $\delta^{13} \mathrm{C}_{\text {DIC }}$ to $\delta^{13} \mathrm{C}_{\mathrm{TOC}}$ is always smaller than the offset of $\delta^{13} \mathrm{C}_{\mathrm{CH}_{4}}$ to $\delta^{13} \mathrm{C}_{\mathrm{TOC}}$ due to the addition of isotopically light DIC by $\mathrm{AOM}$ at the SMT.

In the case of pure autotrophic methanogenesis ( $r=1$; Fig. 3b), the $\delta^{13} \mathrm{C}_{\text {DIC }}$ curves show a similar pattern and a regular spacing for constant differences in $\alpha_{\text {aut }}$ which is due to the linear dependence on $\alpha_{\text {aut }}$. Also, $\delta^{13} \mathrm{C}_{\mathrm{CH} 4}$ shows almost constant values throughout the methanogenic zone, but somewhat more negative values near the SMT, which partially reflects the minimum values in the DIC from which the methane is produced. However, the upward convex curvature in the simulated $\delta^{13} \mathrm{C}_{\mathrm{CH}_{4}}$ profiles just beneath the SMT is never as strong as commonly observed in marine sediments (see discussion below). This is valid under the assumption that no fractionation occurs during AOM, as $\mathrm{CH}_{4}$ is entirely consumed. Compared to acetoclastic methanogenesis $(r=0)$, autotrophic methanogenesis $(\mathrm{r}=1)$ leads to a smaller offset between $\delta^{13} \mathrm{C}_{\mathrm{CH}_{4}}$ and $\delta^{13} \mathrm{C}_{\mathrm{DIC}}$ (Fig. 3c). This can be explained by the stoichiometry (Eq. (13)), where only half of the produced DIC (from fermentation) is fractionated.

In the case of $r=0.5$ (Fig. 3d), where the contribution of acetoclastic and autotrophic methanogenesis are equal, the resulting $\delta^{13} \mathrm{C}$ profiles are intermediate between the two end-members $\mathrm{r}=0$ and $r=1$. In that case, the fractionation factors $\alpha_{a c}$ and $\alpha_{\text {aut }}$ are exchangeable, i.e. exchanging the two fractionation factors leads to almost identical $\delta^{13} \mathrm{C}$ profiles. This can be explained by the production rates of ${ }^{13} \mathrm{CH}_{4}$ and ${ }^{13}$ DIC normalized relative to dTOC/dt, which are only increased or decreased by different fractionation factors but do not change their downcore trend (not shown). As a result, changing the fractionation factors shifts the isotopic composition at all depths equally. Since the resulting $\delta^{13} \mathrm{C}$ production profile is the average of the two different pathways at $\mathrm{r}=0.5$, the fractionation factors are exchangeable.

\subsection{Importance of fractionation factors in natural systems}

Comparison with measured $\delta^{13} \mathrm{C}$ profiles in $\mathrm{CH}_{4}$ and DIC from different DSDP and ODP drill sites at the Blake Ridge in the western North Atlantic Ocean (Fig. 8) shows that our model includes and reproduces the general patterns. $\mathrm{CH}_{4}$ and DIC isotope profiles may approach symmetry along a line defined by the $\delta^{13} \mathrm{C}$ of TOC (arrows) but do not usually exceed this symmetry towards more positive values. Deviations from this symmetry will be discussed further below. Fig. 8 shows that, for the Blake Ridge sediments, this symmetry is commonly reached at around $200 \mathrm{mbsf}$, which is in the range of the modelled domain size. More negative values below this depth may be due to changing sediment composition or gas dynamics, which is not simulated in our model. 
A

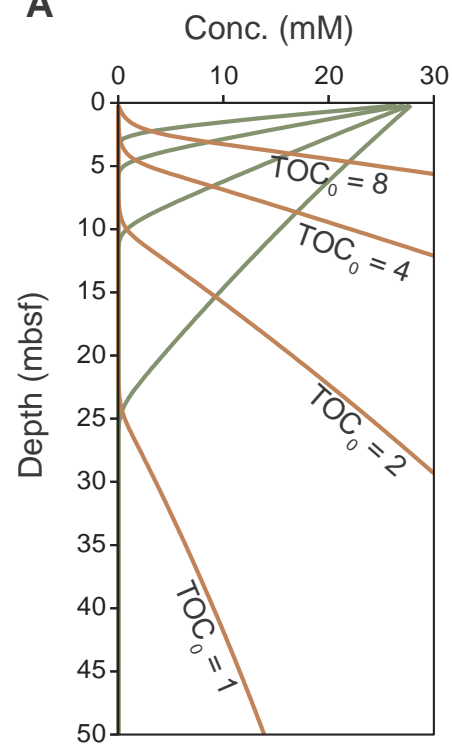

B

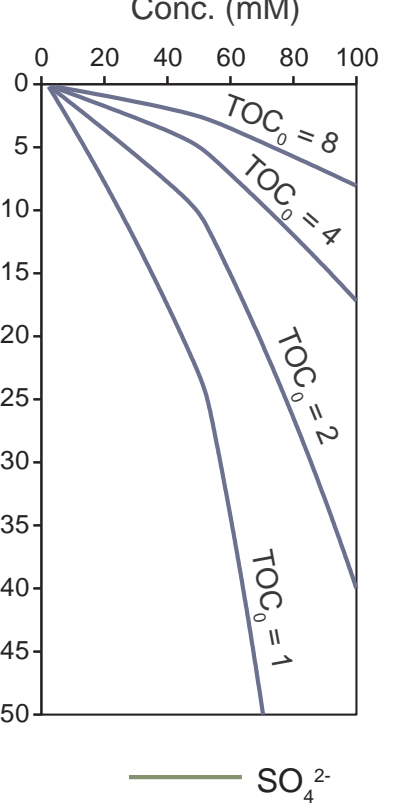

C

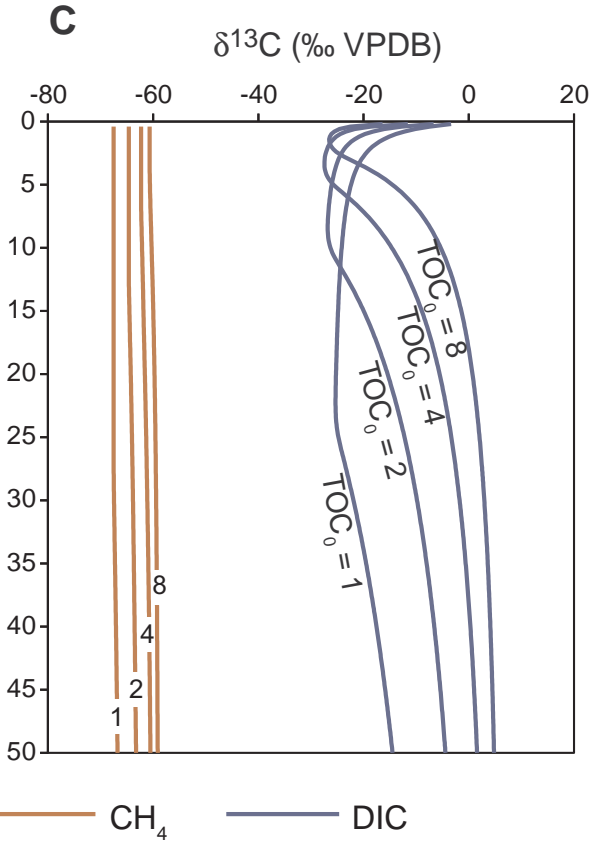

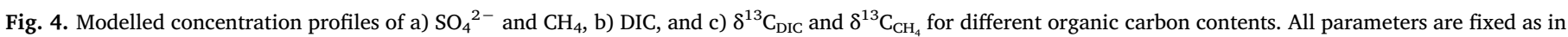

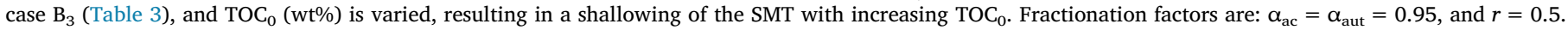

Based on Fig. 3a, an isotopic difference of up to 70\% between DIC and $\mathrm{CH}_{4}$ suggests a fractionation factor $\alpha_{\mathrm{ac}}$ around 0.95 if methanogenesis occurs through the acetoclastic pathway. This is a much stronger fractionation than measured between the two carbon atoms in acetate (7-14\%; Blair and Carter Jr., 1992; Sugimoto and Wada, 1993) and stronger than fractionation observed in culture experiments $\left(\alpha_{\mathrm{ac}} \approx 0.98\right.$; Table 2). This suggests that either the intramolecular isotopic difference is larger in situ than in the experiments or other fractionation mechanisms (e.g., partial equilibrium fractionation) may be operative.

As it is generally found that hydrogenotrophic methanogenesis is predominant in marine settings (e.g. Parkes et al., 2007; Jørgensen and Parkes, 2010; Beulig et al., 2018), stronger fractionation $\left(\alpha_{\text {aut }} \approx 0.93\right)$ would be necessary to reach an isotopic difference of $70 \%$ between DIC and $\mathrm{CH}_{4}$ (cf. Fig. 3b). Such fractionation would be larger than known from most culture experiments, even if the additional fractionation of ca. 9\%o between $\mathrm{CO}_{2}$ and $\mathrm{HCO}_{3}{ }^{-}$is taken into account. The fractionation factors available from culture experiments (e.g. Krzycki et al., 1987; Botz et al., 1996; Londry et al., 2008; Table 2) only consider the hydrogenotrophic step, not taking into account the excess $\mathrm{CO}_{2}$ from $\mathrm{H}_{2}$ production during fermentation. Since the amount of $\mathrm{CO}_{2}$ produced is twice as large as the amount of $\mathrm{CO}_{2}$ consumed during hydrogenotrophic methanogenesis, the isotope difference between DIC and $\mathrm{CH}_{4}$ resulting from a particular $\alpha_{a u t}$ is much smaller than it appears from culture experiments. For this reason, the experimentally determined fractionation factors underestimate the fractionation in marine porewater.

Possibly, organisms living in deep sediments may use modified pathways, or fractionation factors are different under conditions of low energy flux. As for the acetoclastic methanogenesis, isotope equilibration may play a role. Such a mechanism has been suggested by Bottinga (1969) and is supported by larger fractionation observed in cultures in stationary phase (Botz et al., 1996; see discussion in Alperin and Hoehler, 2009), but has so far only been observed for AOM (Yoshinaga et al., 2014), as discussed below (Section 4.3).

\subsection{Sensitivity towards organic matter burial and degradation rates}

As discussed in detail in Meister et al. (2013), the burial and degradation rates of TOC control the concentration profiles of sulphate and methane in diffusive systems (Berner, 1978; Arndt et al., 2013 and refs. therein). It is thus to expect that TOC degradation rates also influence the $\delta^{13} \mathrm{C}$ distribution. The most fundamental influences on porewater profiles are the sedimentation rate and the initial TOC $\left(\mathrm{TOC}_{0}\right)$, i.e. the content of organic carbon at the sediment surface. As illustrated in Fig. 4, increasing $\mathrm{TOC}_{0}$ contents from 1 to $8 \mathrm{wt} \%$ lead to a shoaling of the SMT and an increase of the contribution of methanogenesis to the overall organic matter degradation. Due to the higher influence of methanogenesis, more isotopically heavy DIC is produced, shifting the $\delta^{13} \mathrm{C}_{\mathrm{CH}_{4}}-\delta^{13} \mathrm{C}_{\text {DIC }}$ couple in the methanogenic zone towards symmetry relative to the $\delta^{13} \mathrm{C}_{\mathrm{TOC}}$. Under steady-state conditions, this symmetry is never exceeded towards more positive values.

It is also observed in our model that the $\delta^{13} \mathrm{C}_{\text {DIC }}$ is always near to $\delta^{13} \mathrm{C}_{\mathrm{TOC}}$ at the SMT. This is explained by the balance between the upward diffusion of isotopically heavy DIC from the methanogenic zone and the production of isotopically light DIC by AOM. Under steady-state conditions the amount of methane produced at depth is the same as the amount consumed by AOM, such that the net isotope effect is zero. Extremely negative $\delta^{13} \mathrm{C}_{\text {DIC }}$ values, as commonly observed at the SMT (e.g., Fig. 8), should not occur according to our steady-state model (see discussion below).

Changes in the sedimentation rate affect $\mathrm{dTOC} / \mathrm{dz}$ in the same way as do changes in $\mathrm{TOC}_{0}$, leading to an expansion or compression of the TOC degradation curve with depth (Eq. (8)). Accordingly, sedimentation rate affects the depth of the SMT in the same way as TOC $_{0}$ (Meister et al., 2013). As sedimentation rates are orders of magnitude lower than diffusion rates, the contribution of the burial velocity to solute transport can mostly be neglected. Only at very high sedimentation rates, a significant amount of $\mathrm{CH}_{4}$ and DIC is removed by burial. Since DIC concentration is higher than $\mathrm{CH}_{4}$ concentration in the methanogenic zone, more DIC is removed by burial export. This affects the mass balance at steady state, leading to lower $\delta^{13} \mathrm{C}_{\text {DIC }}$ values at the SMT (Fig. S2a). A similar effect is observed at lower porosity (Fig. S2b), as also low porosity supports the burial export due to lower sediment diffusion coefficients. As mentioned above, a decreasing porosity with depth does not fundamentally change isotope profiles of $\mathrm{CH}_{4}$ and DIC (Fig. S2c, d). The depth of the SMT is sensitive in particular to the porosity at shallow SMT depth, which would be expected, as slower diffusion at lower porosity leads to steeper gradients. Negative $\delta^{13} \mathrm{C}_{\mathrm{DIC}}$ values at the SMT 
A

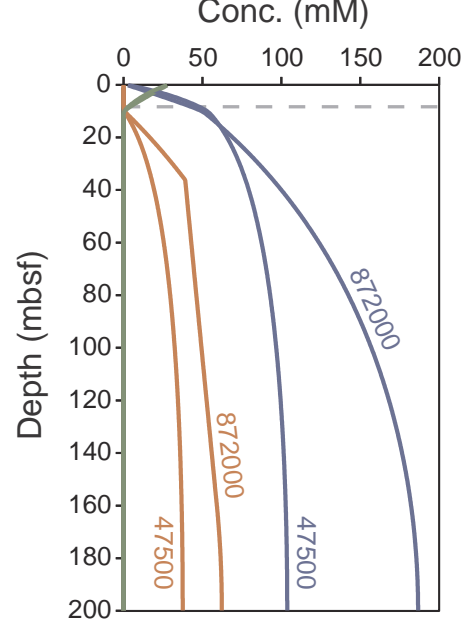

B

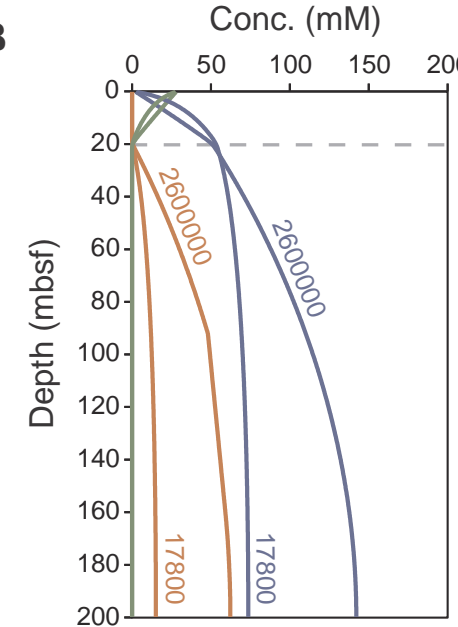

$\delta^{13} \mathrm{C}(\% \circ \mathrm{VPDB})$

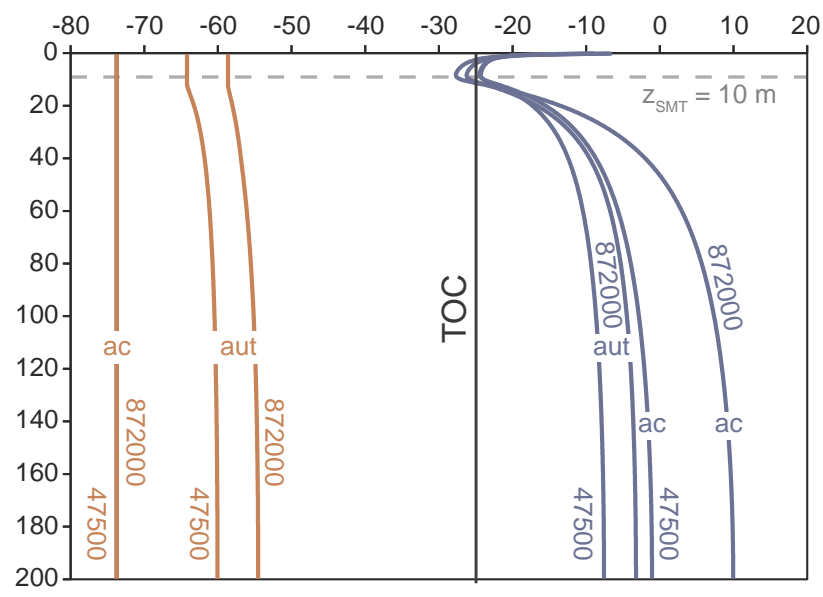

$\delta^{13} \mathrm{C}(\% \circ \mathrm{VPDB})$

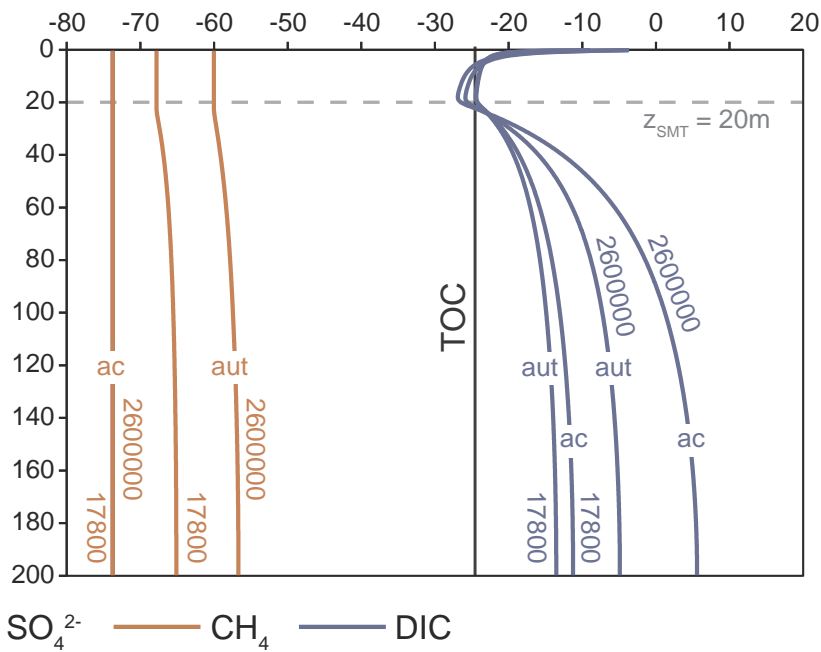

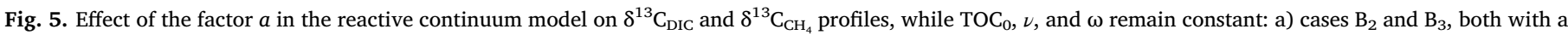

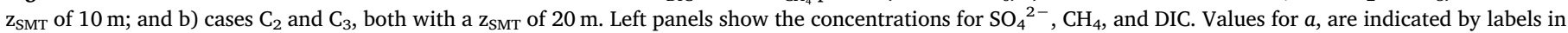

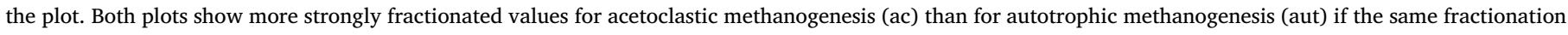
factor of 0.95 is used.

result from low porosity at greater depth in the same way as for different constant porosities. Changing diffusion rate due to increasing temperature with depth has only a minor effect on the simulated isotope profiles (Fig. S2e).

Besides organic matter content and burial rate, also organic matter reactivity has an influence on isotopic distributions. The degradation of organic matter is most likely not limited (and thus not controlled) by the terminal electron accepting processes (TEAP) but rather by the rate of hydrolysis and breakdown of macromolecular compounds (cf. Horsfield et al., 2006; Beulig et al., 2018). Organic matter degradation rates have been described as a function of depth using different models, such as the reactive continuum model (Boudreau and Ruddick, 1991) used in our study. In that model, downcore degradation is essentially controlled by sedimentation rate and by the two parameters $a$ and $\nu$. These parameters affect the concentration profiles of sulphate and methane (Meister et al., 2013) and also influence the $\delta^{13} \mathrm{C}$ distribution.

Here we first address the parameter $a$, which stands in the RC model for the average lifetime of the more reactive compounds. Fig. 5 shows pairs of curves for two different values of $a$ at the same SMT depth (at $10 \mathrm{~m}$ in panel A and at 20 in panel B). Both $\delta^{13} \mathrm{C}_{\mathrm{CH}_{4}}$ and $\delta^{13} \mathrm{C}_{\mathrm{DIC}}$ curves are shifted towards more positive values by a larger $a$. The reason for this lies in the relative contribution of methanogenesis relative to organoclastic sulphate reduction to the overall degradation of organic matter. At large $a$, organic matter is more refractory and decays at greater burial depth, with a larger fraction of the decay in the methanogenic zone, hence leading to more positive $\delta^{13} \mathrm{C}$ values of DIC and $\mathrm{CH}_{4}$. In Fig. 5b, the difference between the two values of $a$ is larger than in Fig. 5a and, accordingly, larger shifts in $\delta^{13} \mathrm{C}$ values appear.

Differences due to changes in $v$ are generally very small (Fig. S1). However, a larger effect of increasing $\nu$ occurs if $a$ is small (Fig. S1a). In this case, $\delta^{13} \mathrm{C}$ values of DIC become more similar to values in TOC and also the value of the $\mathrm{CH}_{4}$ become more negative. This is because the decay curve of organic matter is such that only small amounts of reactive organic matter are left once the sediment is buried beneath the SMT and only small amounts of methane are produced (cf. Fig. 1c in Meister et al., 2013). Thus, only small amounts of ${ }^{13} \mathrm{C}$-enriched DIC are produced throughout the methanogenic zone.

\subsection{Effects of carbon burial on measured carbon isotope profiles}

Comparison with measured isotope data in Fig. 8 shows that $\delta^{13} \mathrm{C}$ values of DIC and $\mathrm{CH}_{4}$ reach nearly symmetry with respect to the $\delta^{13} \mathrm{C}$ of TOC. DSDP Site 533 shows $\delta^{13} \mathrm{C}$ profiles in $\mathrm{CH}_{4}$ and $\mathrm{CO}_{2}$ that are similar to the other sites, although the curved sulphate profile (see 
A

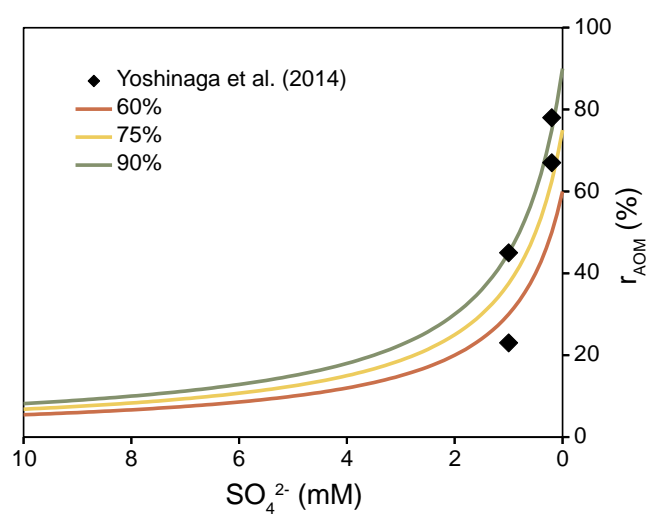

C

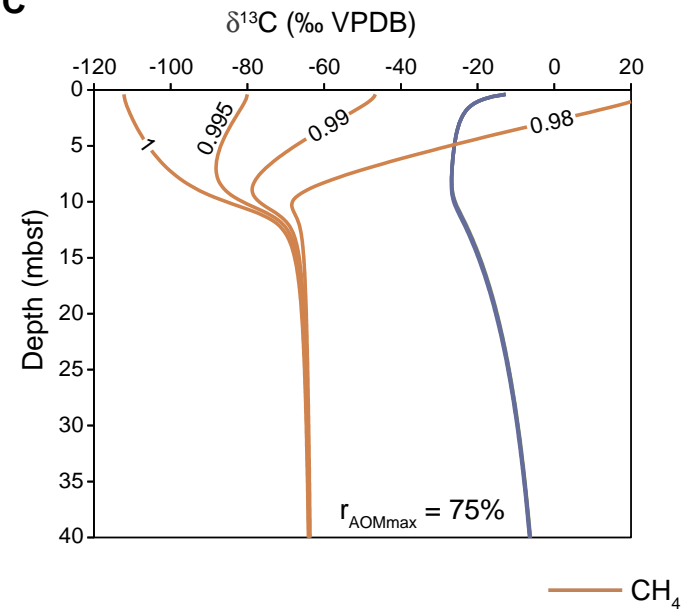

B $\delta^{13} \mathrm{C}(\% \circ$ VPDB)

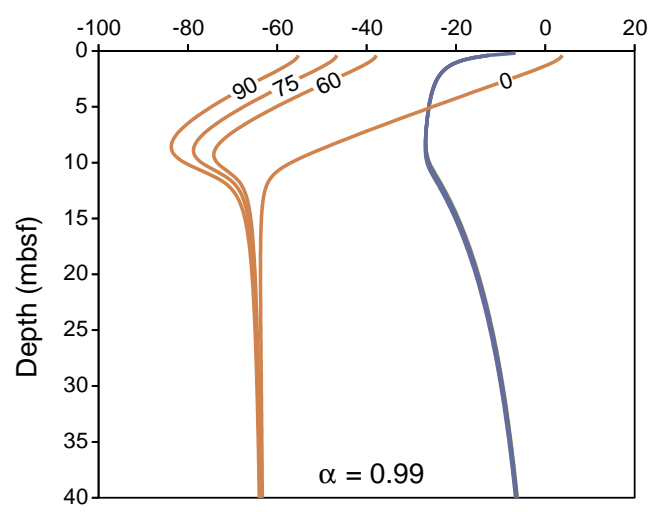

D

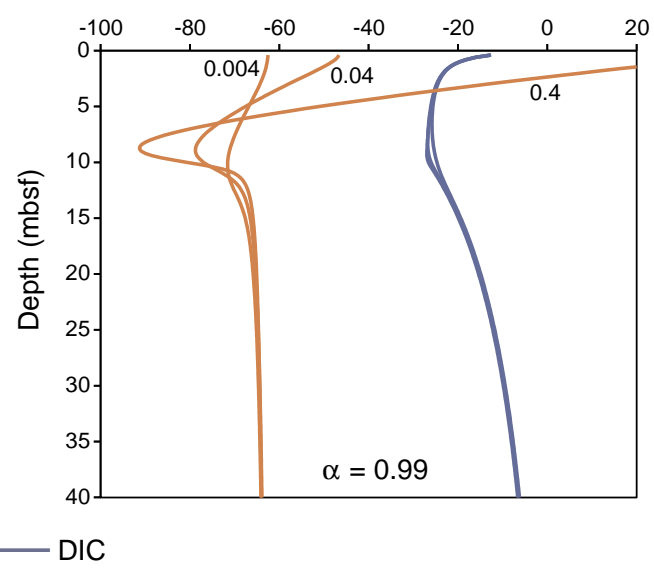

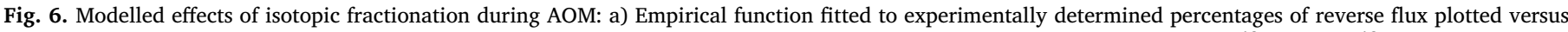

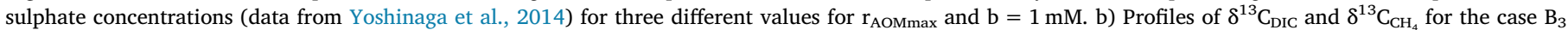

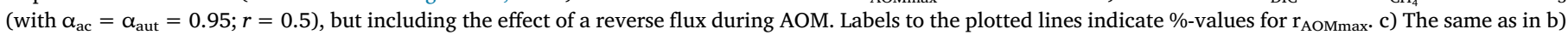

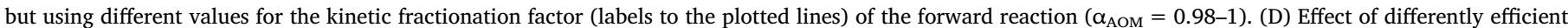
AOM rate. Labels to the plotted lines indicate different values of $\mathrm{k}_{\mathrm{AOM}}$ (the rate constant for AOM).

Conc. (mM)

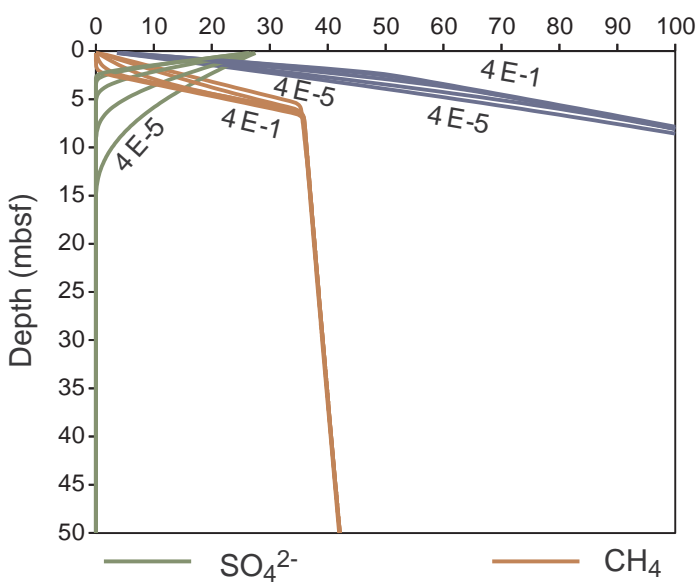

$\delta^{13} \mathrm{C}(\% \circ \mathrm{VPDB})$

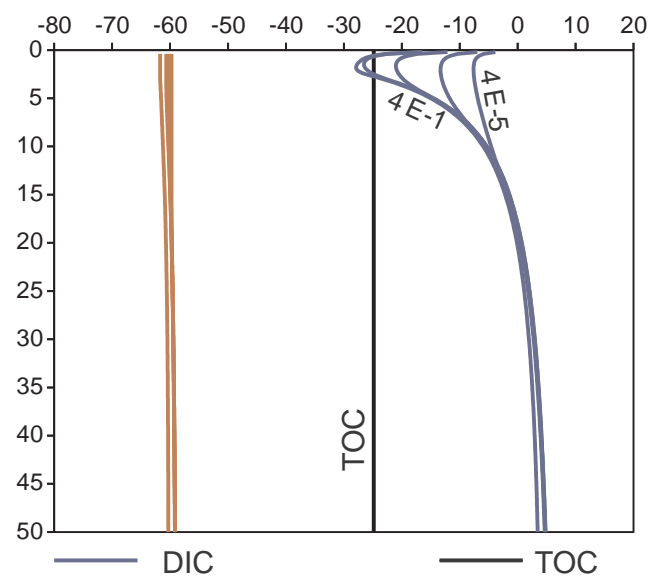

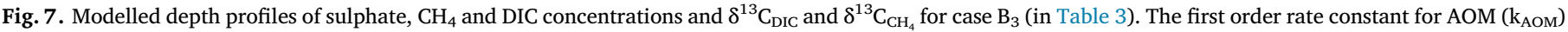

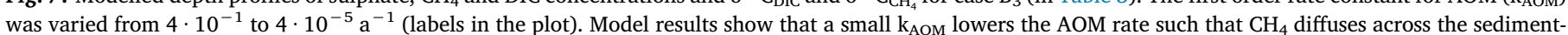

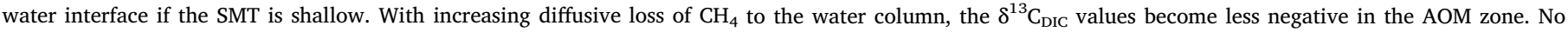
difference in $\delta^{13} \mathrm{C}_{\mathrm{DIC}}$ occurs in the methanogenic zone. 


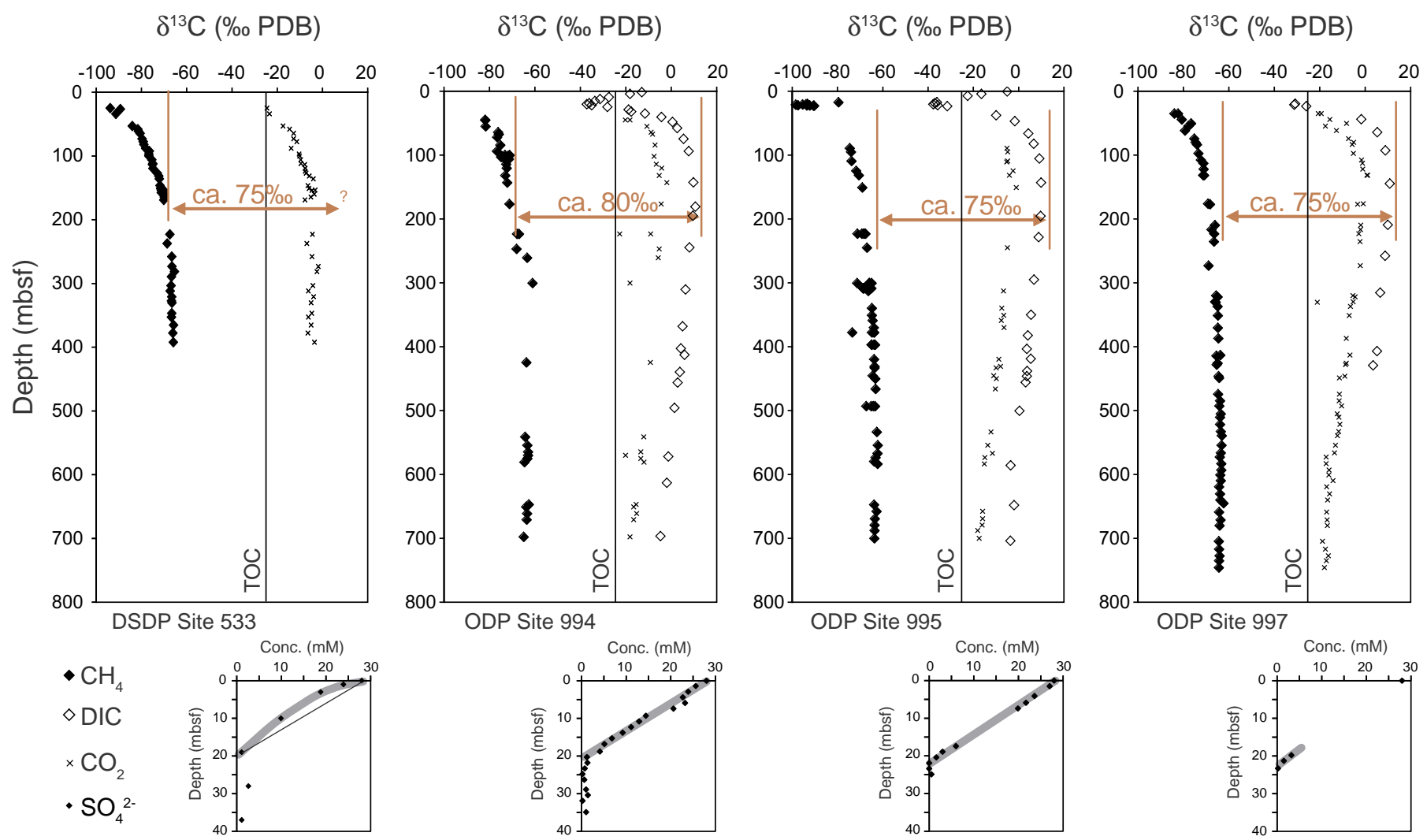

Fig. 8. Measured profiles of $\delta^{13} \mathrm{C}_{\mathrm{DIC}}$ and $\delta^{13} \mathrm{C}_{\mathrm{CH}_{4}}$ from different DSDP and ODP sites at the Blake Ridge: Site 533 (at $3191 \mathrm{~m}$ water depth; DSDP Leg 76; Galimov and Kvenvolden, 1982); Sites 994, 995, and 997 (at 2798, 2779 and $2770 \mathrm{~m}$ water depth, respectively; ODP Leg 164; Paull et al., 2000). Red arrows highlight the difference in isotopic composition between DIC and $\mathrm{CH}_{4}$ in \% VPDB. Insets show the sulphate profiles of each site (data from Jenden and Gieskes, 1983 , and Borowski et al., 2000), and the shading highlights the curved vs. linear shape of the profile in the sulphate reduction zone. (For interpretation of the references to colour in this figure legend, the reader is referred to the web version of this article.)

A

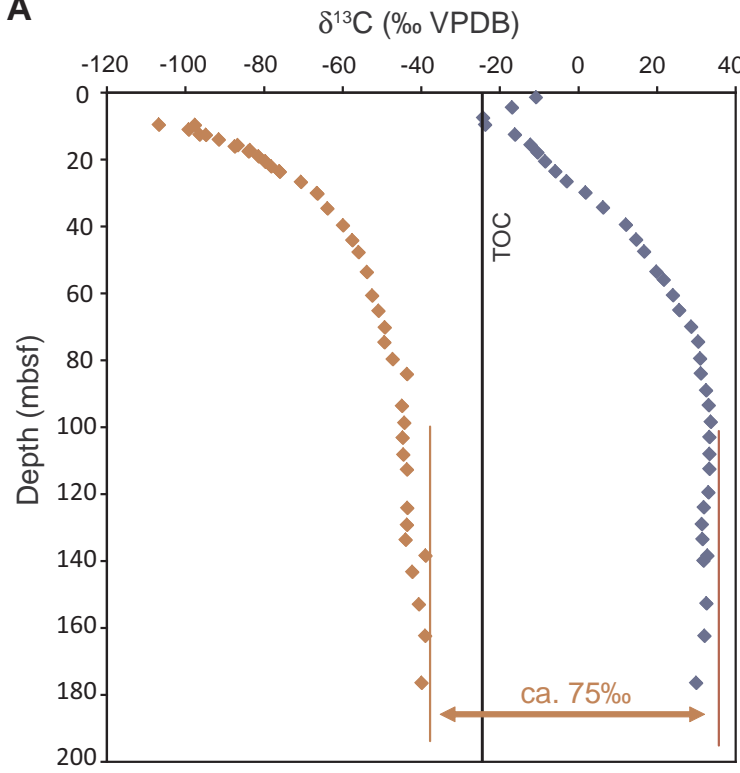

B

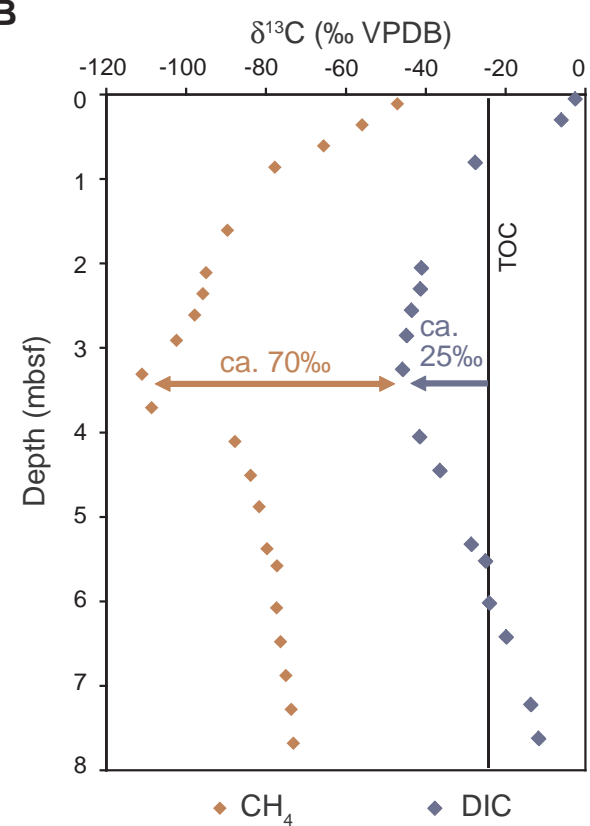

Fig. 9. Measured $\delta^{13} \mathrm{C}_{\mathrm{DIC}}$ and $\delta^{13} \mathrm{C}_{\mathrm{CH}_{4}}$ profiles from two exemplary sites: a) Profiles from the Cascadia Margin offshore of British Columbia (IODP Site U1329; $946 \mathrm{~m}$ water depth; Heuer et al., 2009). The $\delta^{13} \mathrm{C}_{\mathrm{CH}_{4}}$ values show the typical strong negative shift near the SMT at $10 \mathrm{mbsf}$, while the $\delta^{13} \mathrm{C}_{\mathrm{DIC}}$ is near $\delta^{13} \mathrm{C}_{\text {TOC. The two }}$ isotope curves show an asymmetry at depth in the methane zone towards more positive $\delta^{13} \mathrm{C}$ values relative to $\delta^{13} \mathrm{C}_{\mathrm{TOC}}$, which cannot be explained by our model. b) The profile at Site C-2, Bullseye vent, Cascadia Margin (water depth $1311 \mathrm{~m}$; Pohlman et al., 2008) also shows typical negative $\delta^{13} \mathrm{C}_{\mathrm{CH}_{4}}$ values near the SMT at 3-4 mbsf. However, the $\delta^{13} \mathrm{C}_{\mathrm{DIC}}$ values at the SMT are ca. $20 \%$ more negative than $\delta^{13} \mathrm{C}_{\mathrm{TOC}}$, which cannot be explained by our model. 


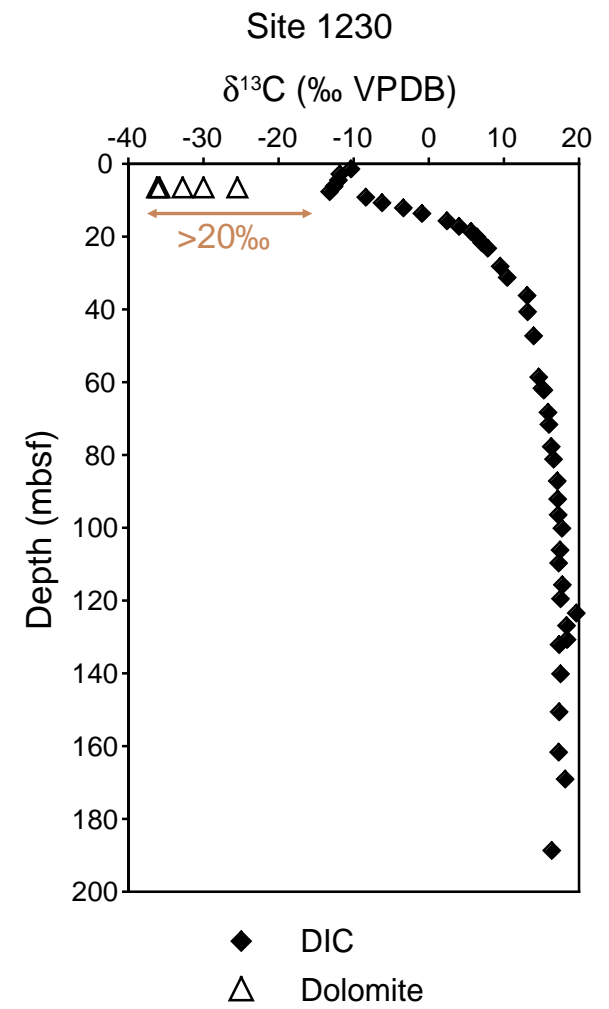

Fig. 10. $\delta^{13} \mathrm{C}_{\text {DIC }}$ and $\delta^{13} \mathrm{C}_{\text {Dolomite }}$ from the Peru Trench ODP Site 1230. The dolomites record strongly negative values from the past. The less negative values in the DIC could be the result of $\mathrm{CH}_{4}$ release to the water column since the time when the dolomites formed.

insets in Fig. 8) would suggest more organic matter being metabolized in the sulphate reduction zone and thus producing more negative $\delta^{13} \mathrm{C}$. Perhaps the curved sulphate profile is only transient, while it needs to be taken into account that these Blake Ridge sites are affected by isotopically light methane from underlying gas hydrates (Borowski and Paull, 1999; Borowski et al., 2000). Nevertheless, the symmetrical distribution in carbon isotopes is persistent.

In measured profiles, $\delta^{13} \mathrm{C}_{\text {DIC }}$ values are frequently more negative than $\delta^{13} \mathrm{C}_{\mathrm{TOC}}$ at the SMT (e.g. Figs. 8, 9b, and 10). According to the simulations discussed so far, this could result from higher burial export of isotopically heavy carbon (as DIC). High sedimentation rates on the order of $0.1 \mathrm{~m} / \mathrm{ka}$, perhaps in combination with decreasing porosity with depth in compacted sediment, enhance this effect. However, other effects could play a role, as discussed below.

Overall, it is clear that burial rate and reactivity of organic matter can significantly influence the isotope compositions, even at similar dynamic fractionations. The most positive isotope values in both DIC and $\mathrm{CH}_{4}$ are reached if organic matter contains a large portion of organic matter with low reactivity and, thus, if methanogenesis contributes more strongly to the total organic matter degradation (cf. Meister et al., 2013). Thus, calculations with varying $a$ and $\nu$ place a limit for possible isotope values under given conditions. More positive values measured in sedimentary porewater would thus require additional explanations (as further discussed below).

\subsection{Effects of isotope exchange}

Based on the studies of Holler et al. (2011) and Yoshinaga et al. (2014) we included a partial isotope equilibration between DIC and $\mathrm{CH}_{4}$ due to a reverse flux during AOM. In Fig. $6 \mathrm{~A}, \mathrm{r}_{\mathrm{AOM}}$ is plotted as a function of the $\mathrm{SO}_{4}{ }^{2-}$ concentration fitted to the experimental data. The resulting isotope profiles plotted in Fig. $6 \mathrm{~b}$ (for the same case $\mathrm{B}_{3}$ as described above, but including fractionation during AOM) show the effect of the reverse flux for different values of $r_{A O M m a x}$ from 60 to $90 \%$. The isotope profiles typically show a minimum value for $\delta^{13} \mathrm{C}_{\mathrm{CH}_{4}}$ at the SMT, which is not observed if no reverse flux occurs $\left(\mathrm{r}_{\mathrm{AOM}}=0\right)$. Upward increasing values in the sulphate reduction zone are due to kinetic fractionation during the forward reaction. In fact, the isotope profile of $\mathrm{CH}_{4}$ shows a high sensitivity towards $\alpha_{\text {AOM }}$ as shown in Fig. 6c. In other words, to produce the observed isotope profiles only minor fractionation is necessary (in the order of $\alpha_{\mathrm{AOM}}=0.99$ ). This is consistent with the observations of Alperin et al. (1988) and Whiticar (1999) suggesting that apparent kinetic fractionation during AOM is relatively small compared to methanogenesis. The much lower fractionation factor of 0.962, observed by Holler et al. (2009) may be due to particular conditions in the experiment, but it would be too low to produce a realistic $\delta^{13} \mathrm{C}_{\mathrm{CH}_{4}}$ profile. Besides the fractionation factor, also the rate at which AOM occurs affects the shape of the $\delta^{13} \mathrm{C}_{\mathrm{CH}_{4}}$ curve near and above the SMT (Fig. 6d). With increasing rate constant $\left(\mathrm{k}_{\mathrm{AOM}}\right)$ both the negative trend at the SMT and the increasing values above the SMT are more pronounced.

A strong decrease in $\delta^{13} \mathrm{C}_{\mathrm{CH}_{4}}$ that is similar to the decrease in $\delta^{13} \mathrm{C}_{\mathrm{DIC}}$ is commonly observed in measured profiles near the SMT (e.g., Claypool and Kaplan, 1974; Heuer et al., 2009; Yoshinaga et al., 2014; Fig. 9a and b). Also an upward increase in $\delta^{13} \mathrm{C}_{\mathrm{CH}_{4}}$ in the sulphate reduction zone is commonly observed in measured profiles (Pohlman et al., 2008; Coffin et al., 2014), which is in accordance with a small kinetic fractionation effect during AOM. Arrows in Figs. 8 and 9 indicate an offset of ca. 75\% at the SMT and below, which is near to the offset expected if $\mathrm{CH}_{4}$ and DIC are in isotopic equilibrium.

In the model, such a large offset at the SMT is nearly reached if an isotopic equilibration due to a reverse AOM flux is taken into account. The offset is due to strongly negative $\delta^{13} \mathrm{C}_{\mathrm{CH}_{4}}$ values at the SMT, while $\delta^{13} \mathrm{C}_{\text {DIC }}$ remains unaffected. DIC is not sensitive to a reverse flux because its pool size is much larger, and $\mathrm{CH}_{4}$ is usually almost quantitatively converted to DIC. Even though pure autotrophic methanogenesis $(r=1)$ also generates a small curvature of the $\delta^{13} \mathrm{C}_{\mathrm{CH} 4}$ profile towards more negative values near the SMT (e.g. Fig. 3b), the effect of the reverse flux by AOM is much larger and is required in order to explain an isotopic difference between $\delta^{13} \mathrm{C}_{\mathrm{CH}_{4}}$ and $\delta^{13} \mathrm{C}_{\text {DIC }}$ near equilibrium fractionation, as observed in the measured profiles.

Also at greater depth below the SMT, observed offsets between $\delta^{13} \mathrm{C}_{\mathrm{CH}_{4}}$ and $\delta^{13} \mathrm{C}_{\text {DIC }}$ in measured profiles are suspiciously near to the calculated thermodynamic equilibrium fractionation at low temperature based on the equation of Horita (2001). These offsets are reached despite the fact that experimentally determined fractionation factors of methanogenesis are significantly smaller. The finding of isotopic exchange as part of the AOM pathway (Holler et al., 2011) raises the question whether partial equilibrium fractionation may also play a role in the methanogenic pathways. This could occur in natural sub-seafloor biosphere settings under strong substrate limitation, such that the pathways become reversible. Such an equilibration does not occur abiotically under Earth surface conditions. Isotopic equilibration may occur in gas phase, e.g. in fumarolic systems (Fiebig et al., 2004), but equilibrium fractionation would be much smaller due to higher temperatures. Such conditions do not normally occur in organic carbon-rich ocean margin sediments.

While the possibility of equilibrium fractionation is still under dispute, a fractionation mechanism related to the activation of coenzyme$\mathrm{M}$ was suggested in a preliminary study (Wegener et al., 2017). Even then, an equilibration step would have to occur somewhere in the pathway to explain strongly negative $\delta^{13} \mathrm{C}_{\mathrm{CH}_{4}}$ at the SMT, which otherwise would require an inverse kinetic fractionation effect. Further experimental work will be essential to clarify the fractionation mechanisms. 


\subsection{Methane gas transport}

Exsolution and advective transport of $\mathrm{CH}_{4}$ and $\mathrm{CO}_{2}$ gas bubbles may have a major influence on $\delta^{13} \mathrm{C}$ distributions. This was already concluded in earlier studies (e.g. Claypool and Kaplan, 1974; Paull et al., 2000) based on closed-system models. Methane is rather poorly soluble in seawater and the solubility limit is often reached in methanogenic sediments. The solubility curve can be calculated, as explained above, as a function of pressure, temperature, and salinity. Gas bubble rise is included in the model by an upward advection term. The upward advection simulated here represents an extreme case, where all $\mathrm{CH}_{4}$ gas continuously rises upwards. The released $\mathrm{CH}_{4}$ rises upwards by buoyancy until it reaches a zone below the SMT where concentrations are lower than solubility at the in situ hydrostatic pressure and where the methane readily dissolves. A sharp kink occurs in the $\mathrm{CH}_{4}$ concentration profile where saturation is reached (e.g. Fig. 5, left panels). The transport by rising gas bubbles has no effect on the $\delta^{13} \mathrm{C}_{\mathrm{CH}_{4}}$ profiles because the production of gas is slow (coupled to the rate of methanogenesis) and the transported gas has an isotopic composition very similar to the upward diffusing $\mathrm{CH}_{4}$. The difference in molecular diffusion rate between the two isotopologues is very small, although some of the isotopically light methane could travel more rapidly due to adsorption/desorption effects in organic carbon rich sediments (Zhang and Krooss, 2001; Xia and Tang, 2012). Our model thus shows that under steady-state conditions and assuming rapid dissolution kinetics for $\mathrm{CH}_{4}$ in water, $\mathrm{CH}_{4}$-gas rise has an insignificant effect on the isotopic profiles.

Under natural conditions, bubbles are to a large extent trapped in the sediment by capillary forces, but may escape episodically if buoyant forces exceed capillary forces and drive $\mathrm{CH}_{4}$ bubbles upwards (e.g. through fractures or other zones of weakness; e.g. Rosner and Epstein, 1972; Garg et al., 2008; Boudreau et al., 2012), causing non-steadystate conditions. Moreover, due to the sudden rise and slow dissolution kinetics (cf. Mogollón et al., 2009), parts of the $\mathrm{CH}_{4}$ may bypass the sulphate reduction zone. This portion of $\mathrm{CH}_{4}$ would thus not undergo AOM but escape to the water column. This effect could lead to less negative $\delta^{13} \mathrm{C}_{\mathrm{CH} 4}$, and perhaps also more positive $\delta^{13} \mathrm{C}_{\text {DIC }}$. It could for example explain the positive shift in $\delta^{13} \mathrm{C}_{\mathrm{CH}_{4}}$ and $\delta^{13} \mathrm{C}_{\text {DIC }}$ at IODP Site U1329 at the Cascadia Margin (Heuer et al., 2009; Fig. 9a), where $\mathrm{CH}_{4}{ }^{-}$ seepage occurs. Another example, where $\mathrm{CH}_{4}$ escape causes strong $\delta^{13} \mathrm{C}$ increase in both organic and inorganic carbon pools, is in Lagoa Salgada, a coastal ephemeral lake in Brazil (Birgel et al., 2014). Due to low $\mathrm{SO}_{4}{ }^{2-}$ content in the brackish water, AOM does not fully prevent $\mathrm{CH}_{4}$ from escaping.

Also a significant amount of $\mathrm{CH}_{4}$ could be transported into the modelled domain from greater depth, such as thermogenic methane from thermal degradation of organic matter (Burdige and Komada, 2011). Thermogenic $\mathrm{CH}_{4}$ is less depleted in ${ }^{13} \mathrm{C}$, with $\delta^{13} \mathrm{C}$ values around $-40 \%$ (Whiticar, 1999), and may result in less negative $\delta^{13} \mathrm{C}_{\mathrm{CH}_{4}}$ in the methanogenic zone. Thermogenic $\mathrm{CH}_{4}$ is known to cause seepage at the Cascadia Margin. However, it remains poorly understood how such $\mathrm{CH}_{4}$ influx affects the $\delta^{13} \mathrm{C}_{\text {DIC }}$, since in the methanogenic zone DIC is not produced from $\mathrm{CH}_{4}$. An increase of $\delta^{13} \mathrm{C}_{\text {DIC }}$ in parallel with $\delta^{13} \mathrm{C}_{\mathrm{CH}_{4}}$ as observed in the example of Fig. 9a could be explained if isotopic equilibration occurs as part of the methanogenesis pathway, as discussed above.

While carbon isotope fractionation during formation and dissociation of gas hydrates is probably negligible (Hachikubo et al., 2007; Lapham et al., 2012) we highlight the role of gas hydrate as a capacitor. Gas hydrate may form or dissociate episodically (e.g. Kennett et al., 2000) and, thus, amplify non-steady-state conditions, which could have a significant effect on carbon isotope distributions by adding or removing $\mathrm{CH}_{4}$ from the pool.

If additional $\mathrm{CH}_{4}$ is dissolved at the SMT it may contribute, via $\mathrm{AOM}$, to ${ }^{13} \mathrm{C}$-depleted DIC. This could be a potential mechanism to produce $\delta^{13} \mathrm{C}_{\text {DIC }}$ more negative than $\delta^{13} \mathrm{C}_{\mathrm{TOC}}$, as observed at Bullseye vent (Fig. 9b; Pohlman et al., 2008) or at ODP Site 1230 in the Peru Trench (in carbonates; Fig. 10; Meister et al., 2011). However, it should be noted that strongly negative $\delta^{13} \mathrm{C}_{\mathrm{DIC}}$ values as observed at the Bullseye vent do not always occur at the SMT, as shown by the example of the present porewater profile at the Peru Trench (Fig. 10). $\delta^{13} \mathrm{C}_{\text {DIC }}$ values more negative than $\delta^{13} \mathrm{C}_{\mathrm{TOC}}$ may result from an excess of isotopically light methane advecting, perhaps episodically, into the AOM zone. Non-steady state in AOM rates is indicated by differing $\delta^{13} \mathrm{C}$-values in DIC and in the carbonates preserved from earlier times at ODP Site 1230 (Fig. 10). At the same time, however, sedimentation rates may also have changed over time, inducing a non-steady state in the burial flux of DIC (cf. Contreras et al., 2013). This could equally have led to $\delta^{13} \mathrm{C}_{\text {DIC }}$ more negative than $\delta^{13} \mathrm{C}_{\mathrm{TOC}}$ at the SMT, as shown in the examples in Fig. S2a.

\section{7. $\mathrm{CO}_{2}$ dynamics}

Besides $\mathrm{CH}_{4}$ advection, $\mathrm{CO}_{2}$ dynamics may have a significant effect on carbon isotope profiles. At isotopic equilibrium, $\mathrm{HCO}_{3}{ }^{-}$would be enriched in ${ }^{13} \mathrm{C}$ by about $9 \%$ relative to $\mathrm{CO}_{2}$ (Mook et al., 1974), and $\mathrm{CO}_{2}$ transport could thus cause a significant increase in $\delta^{13} \mathrm{C}_{\mathrm{DIC}}$ as discussed by Paull et al. (2000). $\mathrm{CO}_{2}$ can be transported by degassing into $\mathrm{CH}_{4}$ bubbles. Predicting the exact amount of $\mathrm{CO}_{2}$ degassing is complex and requires a complete speciation of the carbonate system, which is beyond the scope of this study. In addition, the diffusion of $\mathrm{CO}_{2}$ could affect the isotope distributions. While the diffusion constant only shows a minor dependence on isotopic mass (Zeebe, 2011), the diffusion constant of $\mathrm{CO}_{2}$ is about 1.7 times larger than for $\mathrm{HCO}_{3}{ }^{-}$under the simulated conditions (Schulz and Zabel (2006)). Also simulating this effect would require a speciation of the carbonate system. In particular at concentrations of several hundred mmol/l of DIC calculated in our model, and at low $\mathrm{pH}$ prevailing in methanogenic zones (cf. Jourabchi et al., 2005; Soetaert et al., 2007), a significant fraction of the DIC could be in the form of $\mathrm{CO}_{2}$. Also, core sampling using pressure core barrels has shown that a significant part of the $\mathrm{CO}_{2}$ is already lost under in situ conditions (Paull et al., 1996). Apparently, the residual $\mathrm{CO}_{2}$ is still largely in isotopic equilibrium with the DIC (Fig. 8; Paull et al., 2000). Despite these observations, it is unlikely that $\mathrm{CO}_{2}$ escape has a major effect because the carbonate system is efficiently buffered by high alkalinity in the porewater. E.g. $>150 \mathrm{mM}$ alkalinity was measured in the midst of the methanogenic zone at ODP Site 1230, such that about the same amount of DIC is retained as $\mathrm{HCO}_{3}{ }^{-}$. Loss of $\mathrm{CO}_{2}$ would not change the $\delta^{13} \mathrm{C}_{\text {of }} \mathrm{HCO}_{3}{ }^{-}$, and even in an extreme case, where half of the DIC escapes as $\mathrm{CO}_{2}, \delta^{13} \mathrm{C}_{\text {DIC }}$ would only be shifted by $4.5 \%$.

Very often DIC concentrations decrease downwards at greater depth in the methanogenic zone (e.g. Fig. 8). This effect cannot be explained by decreasing DIC production at steady state, but would require a sink of DIC, such as $\mathrm{CO}_{2}$ escape. More likely though, the decrease in DIC is accompanied by a decrease in total alkalinity (e.g. Meister et al., 2011), which can then not be explained by $\mathrm{CO}_{2}$ escape alone. One explanation can be a dilution effect by a deep-seated porewater. At lower total alkalinity, the capacity to retain DIC would be lower.

$\mathrm{CO}_{2}$ escaping from the methanogenic zone would re-equilibrate near the SMT, where the dissolved $\mathrm{CO}_{2}$ concentration is lower due to higher pH (cf. Jourabchi et al., 2005; Soetaert et al., 2007). However, this could not explain $\delta^{13} \mathrm{C}_{\text {DIC }}$ more negative than $\delta^{13} \mathrm{C}_{\mathrm{TOC}}$ at the SMT (Fig. 9b and 10), because $\mathrm{CO}_{2}$ coming from the methanogenic zone is more positive than $\delta^{13} \mathrm{C}_{\mathrm{DIC}}$ at the SMT. If $\mathrm{CO}_{2}$ rise is episodic this would at least temporarily produce more positive values at the SMT. On a long-term, mass balance would result in no effect of gas advection on $\delta^{13} \mathrm{C}_{\text {DIC }}$ at the SMT.

Exsolution of $\mathrm{CO}_{2}$ may also affect the carbonate equilibrium and facilitate precipitation of carbonates. At the same time, acidification through methanogenic $\mathrm{CO}_{2}$ production may cause undersaturation of carbonates. Even though our study does not include a precise 
calculation of the carbonate equilibrium, sensitivity tests assuming unrealistically large carbonate precipitation rates confirm the findings of Chuang et al. (2019) that carbonate precipitation does not significantly affect the isotopic compositions of $\mathrm{CH}_{4}$ and DIC.

Gas bubble dynamics are complex to model (see e.g. Mogollón et al., 2009; Wallmann et al., 2012; Boudreau, 2012) and cannot be accurately reproduced by our model. Nevertheless, our model could address these problems, provided that carbonate equilibrium, gas dynamics and non-steady-state models are included.

\subsection{Sensitivity to metabolic rate constants}

Besides the escape of gas bubbles to the water column, also diffusive escape of $\mathrm{CH}_{4}$ to the water column may play a role (Dale et al., 2008b). A diffusive outflux of $\mathrm{CH}_{4}$ may occur if organic matter mineralization rates in the sediment are very high and the SMT depth accordingly shallow. Methane may then partly by-pass the sulphate reduction zone if AOM kinetics are too slow to effectively retain the high diffusion flux of $\mathrm{CH}_{4}$ (Thang et al., 2013; Andrén et al., 2015). Although $\mathrm{CH}_{4}$ concentration profiles from these locations may suggest that methane is retained in the sediment, episodic gas release may occur. We performed a sensitivity study using different rate constants to evaluate the effect of complete vs. incomplete oxidation of $\mathrm{CH}_{4}$ in the sediment.

Our standard kinetic rate constants used for AOM are the half saturation constant $\mathrm{K}_{\mathrm{S}, \mathrm{AOM}}=1 \mathrm{mM}$ (Arndt et al., 2006) and the first order rate constant $\mathrm{k}_{\mathrm{AOM}}=4 \cdot 10^{-2} \mathrm{a}^{-1}$. Using a lower value for $\mathrm{K}_{\mathrm{S}, \mathrm{AOM}}$, corresponding to a high sulphate affinity (Tarpgaard et al., 2011), did not significantly change the $\mathrm{CH}_{4}$ gradients at the SMT, yet a release of $\mathrm{CH}_{4}$ could result from a small $\mathrm{k}_{\mathrm{AOM}}$. Fig. 7 displays the concentration profiles and $\delta^{13} \mathrm{C}$ of $\mathrm{CH}_{4}$ and DIC for the case $\mathrm{B}_{3}$, assuming four different values for $\mathrm{k}_{\mathrm{AOM}}$ from $4 \cdot 10^{-1}$ to $4 \cdot 10^{-5} \mathrm{a}^{-1}$. Results show no effect of $\mathrm{k}_{\mathrm{AOM}}$ on isotope profiles below the SMT. However, the release of $\mathrm{CH}_{4}$ has a strong effect on the $\delta^{13} C_{\text {DIC }}$ values at the SMT and above. With increasing by-pass of $\mathrm{CH}_{4}$ across the sulphate reduction zone, the $\delta^{13} \mathrm{C}_{\text {DIC }}$ becomes less influenced by isotopically light carbon from AOM.

Consistent with this model outcome, negative $\delta^{13} \mathrm{C}_{\text {DIC }}$ occurs where large amounts of methane are retained at the SMT, such as in the Peru Trench at ODP Site 1230 (Fig. 10). At this site, strong AOM in the past produced DIC with $\delta^{13} \mathrm{C}_{\mathrm{DIC}}$ more negative than $-30 \%$, which became preserved in diagenetic dolomite. This is commonly observed in methane seep settings (e.g. Jørgensen, 1992). In contrast, modern porewater at Site 1230 (Fig. 10) shows values around $-12 \%$, which may be explained by loss of $\mathrm{CH}_{4}$ since the time when dolomite was precipitated.

\section{Conclusions}

The model results presented here have new implications for the interpretation of $\delta^{13} \mathrm{C}$ distributions observed in marine sediments. Fractionation in the methanogenic zone drives $\delta^{13} \mathrm{C}_{\text {DIC }}$ and $\delta^{13} \mathrm{C}_{\mathrm{CH}_{4}}$ towards symmetry with respect to the $\delta^{13} \mathrm{C}_{\mathrm{TOC}}$. Deviation from this symmetry to lower values occurs if most reactive organic matter is consumed in the sulphate reduction zone and only little is buried into the methanogenic zone. Deviation to higher values must be due to other factors than the ones simulated in this study, such as extensive thermogenic $\mathrm{CH}_{4}$ inflow from below or significant escape of isotopically light $\mathrm{CH}_{4}$ to the water column, probably under non-steady-state conditions.

The difference between $\delta^{13} \mathrm{C}_{\text {DIC }}$ and $\delta^{13} \mathrm{C}_{\mathrm{CH}_{4}}$ largely depends on the fractionation during methanogenesis. Fractionation factors determined in culture experiments, which do not take into account the $\mathrm{CO}_{2}$ produced during fermentation, are generally too low to explain the observed isotope difference between $\delta^{13} \mathrm{C}_{\text {DIC }}$ and $\delta^{13} \mathrm{C}_{\mathrm{CH}_{4}}$ in natural porewater profiles. Our study implies that either fractionation effects are stronger under in situ conditions or fractionation mechanisms are different than previously thought. Enzymatically catalysed equilibrium fractionation may occur during methanogenesis in natural sub-seafloor biosphere settings with strong substrate limitation.

Strongly negative $\delta^{13} \mathrm{C}_{\mathrm{CH}_{4}}$ values near the SMT cannot be explained by autotrophic methanogenesis alone, but can be caused by partial isotopic equilibration due to a reverse flux during $\mathrm{AOM}$ under sulphate limitation, as shown in culture experiments. An upward increasing $\delta^{13} \mathrm{C}_{\mathrm{CH}_{4}}$ in the sulphate reduction zone results from kinetic fractionation during AOM, as the reverse flux is largely suppressed at higher sulphate concentrations.

Strongly negative $\delta^{13} \mathrm{C}_{\mathrm{CH}_{4}}$ values at the SMT do not directly affect $\delta^{13} \mathrm{C}_{\text {DIC }}$, which shows values of $\delta^{13} \mathrm{C}_{\mathrm{TOC}}$ under steady-state conditions. However, $\delta^{13} \mathrm{C}_{\text {DIC }}$ more negative than $\delta^{13} \mathrm{C}_{\text {TOC }}$ results from simulations at high sedimentation rate and in combination with low porosity, due to a significant burial flux of isotopically heavy DIC, perhaps in combination with episodic rise of methane from below and non-steady-state conditions.

\section{Acknowledgements}

We thank B. Brunner, K.-U. Hinrichs, G. Wegener, and M. Zabel for constructive discussions. P. Meister was financed by the Marie-Curie Research Training Network "Greenhouse-Gas Removal Apprenticeship and Student Programme" (GRASP, project MRTN-CT-2006-035868), the Swiss National Science Foundation (SNF, project PA00P2-126221), and the Marie-Curie Intra-European Fellowship programme (Project TRIADOL, grant no. 626025). B. Liu and M. Böttcher were supported by the Institute for Baltic Sea Research in Warnemünde (IOW). B.B. Jørgensen was supported by the Max Planck Society, the Danish National Research Foundation, and an ERC Advanced Grant (MICROENERGY, grant agreement no. 294200) under the EU 7th FP. We thank K. Wallmann and several anonymous reviewers for providing comments that helped to substantially improve the manuscript.

\section{Appendix A. Supplementary data}

Supplementary data to this article can be found online at https:// doi.org/10.1016/j.jmarsys.2019.103227.

\section{References}

Alperin, M.J., Hoehler, T.M., 2009. Anaerobic methane oxidation by archaea/sulfatereducing Bacteria aggregates: 2. Isotopic constraints. Am. J. Sci. 309, 958-984.

Alperin, M.J., Reeburgh, W.S., Whiticar, M.J., 1988. Carbon and hydrogen isotope fractionation resulting from anaerobic methane oxidation. Glob. Biogeochem. Cycles 2, 279-288.

Alperin, M.J., Blair, N.E., Albert, D.B., Hoehler, T.M., Martens, C.S., 1992. Factors that control the stable carbon isotopic composition of methane produced in an anoxic marine sediment. Glob. Biogeochem. Cycles 6, 271-291.

Andrén, T., Jørgensen, B.B., Cotterill, C., Green, S., Expedition 347 Scientists, 2015. Baltic Sea Paleoenvironment - Expedition 347 of the mission-specific drilling platform from and to Kiel, Germany. In: Proc. IODP 347, College Station, TX (Integrated Ocean Drilling Program), https://doi.org/10.2204/iodp.proc.347.2015.

Arndt, S., Brumsack, H.-J., Wirtz, K.W., 2006. Cretaceous black shales as active bioreactors: a biogeochemical model for the deep biosphere encountered during ODP leg 207 (Demarara Rise). Geochim. Cosmochim. Acta 70, 408-425.

Arndt, S., Hetzel, A., Brumsack, H.-J., 2009. Evolution of organic matter degradation in cretaceous black shales inferred from authigenic barite: a reaction-transport model. Geochim. Cosmochim. Acta 73, 2000-2022.

Arndt, S., Jørgensen, B.B., LaRowe, D.E., Middelburg, J.J., Pancost, R.D., Regnier, P., 2013. Quantifying the degradation of organic matter in marine sediments: a review and synthesis. Earth Sci. Rev. 123, 53-86.

Berner, R.A., 1978. Sulfate reduction and the role of deposition of marine sediments. Earth Planet. Sci. Lett. 37, 492-498.

Beulig, F., Røy, H., Glombitza, C., Jørgensen, B.B., 2018. Control on rate and pathway of anaerobic organic carbon degradation in the seabed. Proc. Natl. Acad. Sci. 115, $367-372$.

Bhatnagar, P.L., Gross, E.P., Krook, M., 1954. A model for collision processes in gases. I. Small amplitude processes in charged and neutral one-component systems. Phys. Rev. 94, 511-525.

Birgel, D., Meister, P., Lundberg, R., Horat, T., Bontognali, T., Bahniuk, A., Rezende, C., Vasconcelos, C., McKenzie, J.A., 2015. Methanogenesis produces strong 13C-enrichment in stromatolites of Lagoa Salgada, Brazil: A modern analogue for Palaeo-/ Neoproterozoic stromatolites? Geobiology 13, 245-266.

Blair, N.E., Carter Jr., W.D., 1992. The carbon isotope biogeochemistry of acetate from a methanogenic marine sediment. Geochim. Cosmochim. Acta 56, 1247-1258. 
Borowski, W.S., Paull, C.K., Ussler III, W., 1999. Global and local variations of interstitial sulfate gradients in deep-water, continental margin sediments: sensitivity to underlying methane and gas hydrates. Mar. Geol. 159, 131-154. https://doi.org/10.1016/ S0025-3227(99)00004-3.

Borowski, W.S., Hoehler, T.M., Alperin, M.J., Rodriguez, N.M., Paull, C.K., 2000. Significance of anaerobic methane oxidation in methane-rich sediments overlying the Blake ridge gas hydrates. In: Paull, C.K., Matsumoto, R., Wallace, P.J., Dillon, W.P. (Eds.), Proc. ODP, Sci. Results. vol. 164. Ocean Drilling Program, College Station, TX, pp. 87-99.

Bottinga, Y., 1969. Calculated fractionation factors for carbon and hydrogen isotope exchange in the system calcite-carbon dioxide-graphite-methane-hydrogen-water vapour. Geochim. Cosmochim. Acta 33, 49-64.

Botz, R., Pokojski, H.-D., Schmitt, M., Thomm, M., 1996. Carbon isotope fractionation during bacterial methanogenesis by $\mathrm{CO}_{2}$ reduction. Org. Geochem. 25, 255-262.

Boudreau, B.P., 1997. Diagenetic Models and their Implementation: Modelling Transport and Reactions in Aquatic Sediments. Springer, Berlin, Heidelberg, New York.

Boudreau, B.P., 2012. The physics of bubbles in surficial, soft, cohesive sediments. Mar. Pet. Geol. 38, 1-18.

Boudreau, B.P., Ruddick, B.R., 1991. On a reactive continuum representation of organic matter diagenesis. Am. J. Sci. 291, 507-538.

Boudreau, B.P., Westrich, J.T., 1984. The dependence of bacterial sulfate reduction on sulfate concentration in marine sediments. Geochim. Cosmochim. Acta 48, 2503-2516.

Brand, W.A., Coplen, T.B., 2012. Stable isotope deltas: tiny, yet robust signatures in nature. Isot. Environ. Health Stud. 48, 393-409.

Burdige, D.J., Komada, T., 2011. Anaerobic oxidation of methane and the stoichiometry of remineralization processes in continental margin sediments. Limnol. Oceanogr. 56, 1781-1796.

Chatterjee, S., Chatterjee, Dickens, G.R., Bhatnagar, G., Chapman, W.G., Dugan, B., Snyder, G.T., Hirasaki, G.J., 2011. Pore water sulfate, alkalinity, and carbon isotope profiles in shallow sediment above marine gas hydrate systems: a numerical modeling perspective. J. Geophys. Research 116, B09103, 25 p.

Chuang, P.-C., Yang, T.F., Wallmann, K., Matsumoto, R., Hu, C.-Y., Chen, H.-W., Lin, S., Sun, C.-H., Li, H.-C., Wang, Y., Dale, A.W., 2019. Carbon isotope exchange during anaerobic oxidation of methane (AOM) in sediments of the northeastern South China Sea. Geochim. Cosmochim. Acta 246, 138-155. https://doi.org/10.1029/ 2011JB008290.

Claypool, G.E., Kaplan, I.R., 1974. The origin and distribution of methane in marine sediments. In: Kaplan, I.R. (Ed.), Natural Gases in Marine Sediments. Plenum Press, New York, pp. 99-140.

Claypool, G.E., Presley, B.J., Kaplan, I.R., 1973. In: Creager, J.S., Scholl, D.W. (Eds.), Gas Analyses in Sediment Samples from Legs 10, 11, 13, 14, 15, 18, and 19. Init. Reports DSDP. vol. 19. U.S. Gov. Printing Office, Washington, pp. 879-884.

Coffin, R.B., Hamdan, L.J., Smith, J.P., Rose, P.S., Plummer, R.E., Yoza, B., Pecher, I., Montgomery, M.T., 2014. Contribution of vertical methane flux to shallow sediment carbon pools across Porangahau ridge, New Zealand. Energies 7, 5332-5356.

Contreras, S., Meister, P., Liu, B., Prieto-Mollar, X., Hinrichs, K.-U., Khalili, A., Ferdelman, T.G., Kuypers, M.M.M., Jørgensen, B.B., 2013. Strong glacial-interglacial variation of sub-seafloor microbial activity on the Peruvian shelf. Proc. Natl. Acad. Sci. 110, 18098-18103.

Dale, A.W., Van Cappellen, P., Aguilera, D.R., Regnier, P., 2008b. Methane efflux from marine sediments in passive and active margins: estimations from bioenergetic reaction-transport simulations. Earth Planet. Sci. Letters 265, 329-344.

Dale, A.W., Aguilera, D.R., Regnier, P., Fossing, H., Knab, N.J., Jørgensen, B.B., 2008a. Seasonal dynamics of the depth and rate of anaerobic oxidation of methane in Aarhus Bay (Denmark) sediments. J. Mar. Res. 66, 127-155.

Dickens, G.R., 1997. A blast of gas in the latest Paleocene: simulating first-order effects of massive dissociation of oceanic methane hydrate. Geology 25, 259-262.

Dickens, G.R., 1999. The blast in the past. Nature 401, 752-755.

Duan, Z., Møller, N., Weare, J.H., 1992. An equation of state fort he $\mathrm{CH}_{4}-\mathrm{CO}_{2}-\mathrm{H}_{2} \mathrm{O}$ system: I. pure systems from 0 to $1000^{\circ} \mathrm{C}$ and 0 to 800 bar. Geochim. Cosmochim. Acta 56, 2605-2617.

Einsele, G., 2000. Sedimentary Basins - Evolution, Facies, and Sediment Budget, 2nd Edition. Springer, Berlin Heidelberg 792 pp.

Fiebig, J., Chiodini, G., Caliro, S., Rizzo, A., Spangenberg, J., Hunziker, J.C., 2004. Chemical and isotopic equilibrium between $\mathrm{CO}_{2}$ and $\mathrm{CH}_{4}$ in fumarolic gas discharges: generation of $\mathrm{CH}_{4}$ in arc magmatic-hydrothermal systems. Geochim. Cosmochim. Acta 68, 2321-2334.

Galimov, E.M., 2006. Isotope organic geochemistry. Org. Geochem. 37, 1200-1262.

Galimov, E.M., Kvenvolden, K.A., 1982. Concentrations and carbon isotopic compositions of $\mathrm{CH}_{4}$ and $\mathrm{CO}_{2}$ in gas from sediments of the Blake Outer Ridge, Deep Sea drilling project leg 76. In: Sheridan, R.E., Gradstein, F.M. (Eds.), Init. Repts. DSDP 76 , Washington. U.S. Govt. Printing Office, pp. 403-407.

Garg, S.K., Prichett, J.W., Katoh, A., Baba, K., Fuji, T.A., 2008. A mathematical model for constitutive properties governing multiphase flow in porous media. J. Geophys. Res. 113https://doi.org/10.1029/2006JB004768. B01201.

Gelwicks, J.T., Risatti, J.B., Hayes, J.M., 1994. Carbon isotope effects associated with aceticlastic methanogenesis. Appl. Environ. Microbiol. 60, 467-472.

Goldhaber, M.B., 1974. Equilibrium and Dynamic Aspects of the Marine Geochemistry of Sulfur. PhD thesis. Univ. California, Los Angeles.

Hachikubo, A., Kosaka, T., Kida, M., Krylov, A., Sakagami, H., Minami, H., Takahashi, N., Shoji, H., 2007. Isotopic fractionation of methane and ethane hydrates between gas and hydrate phases. Geophys. Res. Lett. 34 (L21502), 1-5.

Hayes, J.M., Waldbauer Jr., J., 2006. The carbon cycle and associated redox processes through time. Philosophical Transactions of the Royal Society, B-Biological Sciences 361, 931-950.
Heuer, V.B., Pohlman, J.W., Torres, M.E., Elvert, M., Hinrichs, K.-U., 2009. The stable carbon isotope biogeochemistry of acetate and other dissolved carbon species in deep sub-seafloor sediments at the northern Cascadia Margin. Geochim. Cosmochim. Acta 73, 3323-3336.

Hoefs, J., 2018. Stable Isotope Geochemistry, 8th. ed. Springer International Publishing (437 pp).

Holler, T., Wegener, G., Knittel, K., Boetius, A., Brunner, B., Kuypers, M., Widdel, F., 2009. Substantial ${ }^{13} \mathrm{C} /{ }^{12} \mathrm{C}$ and $\mathrm{D} / \mathrm{H}$ fractionation during anaerobic oxidation of methane by marine consortia enriched in vitro. Environ. Microbiol. Rep. 1, 370-376.

Holler, T., Wegener, G., Niemann, H., Deusner, C., Ferdelman, T.G., Boetius, A., Brunner, B., Widdel, F., 2011. Carbon and sulfur back flux during anaerobic microbial oxidation of methane and coupled sulfate reduction. Proc. Natl. Acad. Sci. 108, 1484-1490.

Horita, J., 2001. Carbon isotope exchange in the system $\mathrm{CO}_{2}-\mathrm{CH}_{4}$ at elevated temperatures. Geochim. Cosmochim. Acta 65, 1907-1919.

Horsfield, B., Schenk, H.J., Zink, K., Ondrak, R., Dieckmann, V., Kallmeyer, J., Mangelsdorf, K., di Primio, R., Wilkes, H., Parkes, R.J., Fry, J., Cragg, B., 2006. Living microbial ecosystems within the active zone of catagenesis: implications for feeding the deep biosphere. Earth Planet. Sci. Letters 246, 55-69.

Jenden, P.D., Gieskes, J.M., 1983. Chemical and isotopic composition of interstitial water from deep sea drilling project sites 533 and 534. In: Sheridan, R.E., Gradstein, F.M. (Eds.), Init. Repts. DSDP 76. U.S. Govt. Printing Office, Washington, pp. 453-461.

Jørgensen, B.B., Parkes, R.J., 2010. Role of sulfate reduction and methane for anaerobic carbon cycling in eutrophic fjord sediments (Limfjorden, Denmark). Limnol. Oceanogr. 55, 1338-1352.

Jørgensen, N.O., 1992. Methane-derived carbonate cementation of marine sediments from the Kattegat, Denmark: geochemical and geological evidence. Mar. Geol. 103, $1-13$.

Jourabchi, P., Van Cappellen, P., Regnier, P., 2005. Quantitative interpretation of pH distributions in aquatic sediments: a reaction-transport modeling approach. Am. J Sci. 305, 919-956.

Kelts, K., McKenzie, J.A., 1984. A comparison of anoxic dolomite from deep-sea sediments. Quaternary Gulf of California and Messinian Tripoli Formation of Sicily. In: Dolomites of the Monterey Formation and Other Organic-Rich Units 41. Eds. R.E. Garrison, M. Kastner, D.H. Zenger, Pacific Section SEPM, pp. 19-28. hhttp:// archives.datapages.com/datapac_sepm/057/057001pdfs/19.htm\#purchaseoptions.

Kennett, J.P., Cannariato, K.G., Hendy, I.L., Behl, R.J., 2000. Carbon isotopic evidence for methane hydrate instability during quaternary interstadials. Science 288, 128-133.

Knab, N.J., Dale, A.W., Lettmann, K., Fossing, H., Jørgensen, B.B., 2008. Thermodynamic and kinetic control on anaerobic oxidation of methane in marine sediments. Geochim. Cosmochim. Acta 72, 3746-3757.

Knoll, A.H., Hayes, J.M., Kaufmann, A.J., Swett, K., Lambert, I.B., 1986. Secular variation in carbon isotope ratios from Upper Proterozoic successions of Svalbard and East Greenland. Nature 321, 832-838.

Krzycki, J.A., Kenealy, W.R., DeNiro, M.J., Zeikus, J.G., 1987. Stable carbon isotope fractionation by Methanosarcina barkeri during methanogenesis from acetate, methanol or carbon dioxide-hydrogen. Appl. Environ. Microbiol. 53, 2597-2599.

Lapham, L.L., Wilson, R.M., Chanton, J.P., 2012. Pressurized laboratory experiments show no stable carbon isotope fractionation of methane during gas hydrate dissolution and dissociation. Rapid Commun. Mass Spectrom. 26, 32-36.

Londry, K.L., Des Marais, D.J., 2003. Stable carbon isotope fractionation by sulfate-reducing bacteria. Appl. Env. Microbiol. 69, 2942-2949.

Londry, K.L., Dawson, K.G., Grover, H.D., Summons, R.E., Bradley, A.S., 2008. Stable carbon isotope fractionation between substrates and products of Methanosarcina barkeri. Org. Geochem. 39, 608-621.

Malone, M.J., Claypool, G., Martin, J.B., Dickens, G.R., 2002. Variable methane fluxes in shallow marine systems over geologic time: the composition and origin of pore waters and authigenic carbonates on the New Jersey shelf. Mar. Geol. 189, 175-196.

Meister, P., 2015. For the deep biosphere, the present is not always the key to the past: what we can learn from the geological record. Terra Nova 27, 400-408.

Meister, P., Bernasconi, S., McKenzie, J.A., Vasconcelos, C., Frank, M., Gutjahr, M., Schrag, D., 2007. Dolomite formation in the dynamic deep biosphere: results from the Peru Margin (ODP Leg 201). Sedimentology 54, 1007-1032.

Meister, P., Bernasconi, S., McKenzie, J.A., Vasconcelos, C., 2008. Sea-level changes control diagenetic dolomite formation in hemipelagic sediments of the Peru Margin. Mar. Geol. 252, 166-173.

Meister, P., Gutjahr, M., Frank, M., Bernasconi, S., McKenzie, J.A., Vasconcelos, C., 2011. Dolomite formation within the methanogenic zone induced by tectonically-driven fluids in the Peru accretionary prism. Geology 39, 563-566.

Meister, P., Liu, B., Ferdelman, T.G., Jørgensen, B.B., Khalili, A., 2013. Control of sulphate and methane distributions in marine sediments by organic matter reactivity. Geochim. Cosmochim. Acta 104, 183-193.

Meister, P., Brunner, B., Picard, A., Böttcher, M.E., Jørgensen, B.B., 2019. Sulphur and carbon isotopes as tracers of past sub-seafloor microbial activity. Nat. Sci. Rep. 9 (604), 1-9.

Mogollón, J.M., L'Heureux, I., Dale, A.W., Regnier, P., 2009. Methane gas-phase dynamics in marine sediments: a model study. Am. J. Sci. 309, 189-220.

Mook, W.G., Bommerson, J.C., Staverman, W.H., 1974. Carbon isotope fractionation between dissolved bicarbonate and gaseous carbon dioxide. Earth Planet. Sci. Lett. $22,169-176$.

Moore, T.S., Murray, R.W., Kurtz, A.C., Schrag, D.P., 2004. Anaerobic methane oxidation and the formation of dolomite. Earth Planet. Sci. Lett. 229, 141-154.

Murata, K.J., Friedman, I., Madsen, B.H., 1969. Isotopic composition of diagenetic carbonates in marine Miocene formations of California and Oregon. USGS Prof. Paper, 614-Bpp. 1-24.

Nauhaus, K., Boetius, A., Krüger, M., Widdel, F., 2002. In vitro demostration of anaerobic 
oxidation of methane coupled to sulphate reduction in sediment from a marine gas hydrate area. Environ. Microbiol. 4, 296-305.

Nissenbaum, A., Presley, B.J., Kaplan, I.R., 1972. Early diagenesis in a reducing fjord, Saanich Inlet, British Columbia - I. Chemical and isotopic changes in major components of interstitial water. Geochim. Cosmochim. Acta 36, 1007-1027.

Parkes, R.J., Cragg, B.A., Banning, N., Brock, F., Webster, G., Fry, J.C., Hornibrook, E., Pancost, R.D., Kelly, S., Knab, N., Jørgensen, B.B., Rinna, J., Weightman, A.J., 2007. Biogeochemistry and biodiversity of methane cycling in subsurface marine sediments (Skagerak, Denmark). Environ. Microbiol. 9, 1146-1161.

Paull, C.K., Matsumoto, R., Wallace, P.J., Shipboard Scientific Party, 1996. Gas hydrate sampling on the Blake Ridge and Carolina Rise. In: Proc. ODP, Init. Repts. vol. 164 Ocean Drilling Program, College Station, TX.

Paull, C.K., Lorenson, T.D., Borowski, W.S., Ussler III, W., Olsen, K., Rodriguez, N.M., 2000. Isotopic composition of $\mathrm{CH}_{4}, \mathrm{CO}_{2}$ species, and sedimentary organic matter within samples from the Blake ridge: Gas source implications. In: Paull, C.K., Matsumoto, R., Wallace, P.J., Dillon, W.P. (Eds.), Proc. ODP, Sci. Results. Ocean Drilling Program, College Station, TX, pp. 164.

Payne, J.L., Lehrmann, D.J., Wei, J., Orchard, M.J., Schrag, D.P., Knoll, A.H., 2004. Large perturbations of the carbon cycle during recovery from the end-Permian extinction. Science 305, 506-509.

Pisciotto, K.A., Mahoney, J.J., 1981. Isotopic survey of diagenetic carbonates. In: Yeats, R.S., Haq, B.U. (Eds.), Init. Repts. DSDP. 63. US Govt Printing Office, Washington, DC, pp. 595-609.

Pohlman, J.W., Ruppel, C., Hutchinson, D.R., Coffin, R.B., 2008. Assessing sulfate reduction and methane cycling in a high salinity pore water system in the northern Gulf of Mexico. Mar. Petrol. Geol. 25, 942-951.

Presley, B.J., Kaplan, I.R., 1971. Interstitial water chemistry: Deep sea drilling project, leg 7. In: Winterer, E.L., Riedel, W.R. (Eds.), Init. Reports DSDP. vol. 7. U.S. Gov. Printing Office, Washington, pp. 883-887.

Presley, B.J., Kaplan, I.R., 1972. In: Hollister, C.D., Ewing, J.I. (Eds.), Interstitial Water Chemistry: Deep Sea Drilling Project, Leg 11. Init. Reports DSDP. vol. 11. U.S. Gov. Printing Office, Washington, pp. 1009-1012.

Richet, P., Bottinga, Y., Javay, M., 1977. A review of hydrogen, carbon, nitrogen, oxygen, sulphur, and chlorine stable isotope fractionation among gaseous molecules. Annu. Rev. Earth Planet. Sci. 5, 65-110.

Rodriguez, N.M., Paull, C.K., Borowski, W.S., 2000. Zonation of authigenic carbonates within gas hydrate-bearing sedimentary sections on the blake ridge: offshore southeastern North America. In: Paull, C.K., Matsumoto, R., Wallace, P.J., Dillon, W.P. (Eds.), Proc. ODP, Sci. Results. vol. 164. Ocean Drilling Program, College Station, TX, pp. 301-312.

Rosner, D.E., Epstein, M., 1972. Effects of interface kinetics, capillary and solute diffusion on bubble growth rates in highly supersaturated liquids. Chem. Eng. Sci. 27, 69-88.

Schidlowski, M., Matzigkeit, U., Krumbein, W.E., 1984. Superheavy organic carbon from hypersaline microbial mats: assimilatory pathway and geochemical implications. Naturwissenschaften 71, 303-308.

Schrag, D.P., Higgins, J.A., Macdonald, F.A., Johnston, D.T., 2013. Authigenic carbonate and the history of the global carbon cycle. Science 339, 540-543.

Schulz, H.D., Zabel, M., 2006. Marine Geochemistry, 2nd. ed. Springer, Berlin Heidelberg New York 574 pp.

Soetaert, K., Hofmann, A.F., Middelburg, J.J., Meysman, F.J.R., Greenwood, J., 2007. The effect of biogeochemical processes on pH. Mar. Chem. 105, 30-51.

Sugimoto, A., Wada, E., 1993. Carbon isotopic composition of bacterial methane in a soil incubation experiment: contributions of acetate and $\mathrm{CO}_{2} / \mathrm{H}_{2}$. Geochim. Cosmochim. Acta 57, 4015-4027.

Sukop, M.C., Thorne Jr., D.T., 2007. Lattice Boltzmann Modeling: An Introduction for Geoscientists and Engineers. Springer, 172 p., (ISBN-10/ASIN:3540279814 or ISBN-

\section{3/EAN:9783540279815).}

Tarpgaard, I.H., Røy, H., Jørgensen, B.B., 2011. Concurrent low- and high-affinity sulfate reduction kinetics in marine sediment. Geochim. Cosmochim. Acta 75, 2997-3010.

Tarpgaard, I.H., Jørgensen, B.B., Kjeldsen, K.U., Røy, H., 2017. The marine sufate reduce desulfobacterium autotrophicum HRM2 can switch between low and high apparent half-saturation constants for dissimilatory sulfate reduction. FEMS Microbiol. Ecol. 93. https://doi.org/10.1093/femsec/fix012.

Thang, N.M., Brüchert, V., Formolo, M., Wegener, G., Ginters, L., Jørgensen, B.B. Ferdelman, T.G., 2013. The impact of sediment and carbon fluxes on the biogeochemistry of methane and sulfur in littoral Baltic Sea sediments (Himmerfjärden, Sweden). Estuar. Coasts 36, 98-115.

Treude, T., Boetius, A., Knittel, K., Wallmann, K., Jørgensen, B.B., 2003. Anaerobic oxidation of methane above gas hydrates at Hydrate Ridge, NE Pacific Ocean. Mar. Ecol. Prog. Ser. 264, 1-14.

Urey, H.C., Greiff, L.J., 1935. Isotopic exchange equilbria. J. Am. Chem. Soc. 57, 321-327.

Wallmann, K., Pinero, E., Burwicz, E., Haeckel, M., Hensen, C., Dale, A., Ruepke, L., 2012. The global inventory of methane hydrate in marine sediments: a theoretical approach. Energies 5, 2449-2498.

Wegener, G., Zabel, M., Kölling, M., Taubner, H., Elvert, M., 2017. Elucidating ${ }^{13} \mathrm{C}$-depleted methane generation during anaerobic methanotrophy. Goldschmidt Abstracts 2017, 4217.

Wehrmann, L.M., Ockert, C., Mix, A., Gussone, N., Teichert, B.M.A., Meister, P., 2016. Multiple onset of methanogenic zones, diagenetic dolomite formation, and silicate alteration under varying organic carbon deposition in Bering Sea sediments (Bowers Ridge, IODP Exp. 323 Site U1341). Deep Sea Research II 125-126, 117-132.

Whiticar, M.J., 1999. Carbon and hydrogen isotope systematics of bacterial formation and oxidation of methane. Chem. Geol. 161, 291-314.

Whiticar, M.J., Faber, E., 1986. Methane oxidation in sediment and water column environments-isotope evidence. Org. Geochem. 10, 759-768.

Whiticar, M.J., Faber, E., Schoell, M., 1986. Biogenic methane formation in marine and freshwater environments: $\mathrm{CO}_{2}$ reduction vs. acetate fermentation - isotope evidence. Geochim. Cosmochim. Acta 50, 693-709.

Wolf-Gladrow, D.A., 2000. Lattice-Gas Cellular Automata and Lattice Boltzmann Models: An Introduction (Lecture Notes in Mathematics). Springer, 308 p., (ISBN-10/ ASIN:3540669736 or ISBN-13/EAN:9783540669739).

Wu, Z., Liu, B., Escher, P., Kowalski, N., Böttcher, M.E., 2018. Carbon diagenesis in different sedimentary environments of the subtropical Beibu gulf, South China Sea. J. Mar. Sys. 186, 68-84.

Xia, X., Tang, Y., 2012. Isotope fractionation of methane during natural gas flow with coupled diffusion and adsorption/desorption. Geochim. Cosmochim. Acta 77, 489-503.

Yoshinaga, M.Y., Holler, T., Goldhammer, T., Wegener, G., Pohlman, J.W., Brunner, B., Kuypers, M.M.M., Hinrichs, K.-U., Elvert, M., 2014. Carbon isotope equilibration during sulphate-limited anaerobic oxidation of methane. Nat. Geosci. 7, 190-194.

Zeebe, R.E., 2007. Modeling $\mathrm{CO}_{2}$ chemistry, $\delta^{13} \mathrm{C}$, and oxidation of organic carbon and methane in sediment porewater: implications for paleo-proxies in benthic foraminifera. Geochim. Cosmochim. Ac. 71, 3238-3256.

Zeebe, R.E., 2011. On the molecular diffusion coefficients of dissolved $\mathrm{CO}_{2}, \mathrm{HCO}_{3}{ }^{-}$, and $\mathrm{CO}_{3}{ }^{2-}$, and their dependence on isotopic mass. Geochim. Cosmochim. Acta 75, $2483-2498$.

Zhang, Q.L., Chang, T.L., Li, W.J., 1990. A calibrated measurement of the atomic-weight of carbon. Chin. Sci. Bull. 35, 290-296.

Zhang, T., Krooss, B.M., 2001. Experimental investigation on the carbon isotope fractionation of methane during gas migration by diffusion through sedimentary rocks a elevated temperature and pressure. Geochim. Cosmochim. Acta 65, 2723-2742. 